\title{
Comparing California Current cetacean-habitat models developed using in situ and remotely sensed sea surface temperature data
}

\author{
E. A. Becker ${ }^{1, *}$, K. A. Forney ${ }^{1}$, M. C. Ferguson ${ }^{2}$, D. G. Foley ${ }^{3,4}$, R. C. Smith ${ }^{5}$, \\ J. Barlow ${ }^{2}$, J. V. Redfern' \\ ${ }^{1}$ NOAA, Southwest Fisheries Science Center, 110 Shaffer Rd, Santa Cruz, California 95060, USA \\ ${ }^{2}$ NOAA, Southwest Fisheries Science Center, 3333 N. Torrey Pines Ct., La Jolla, California 92037, USA \\ ${ }^{3}$ Joint Institute for Marine and Atmospheric Research, University of Hawaii, 1000 Pope Rd, Honolulu, Hawaii 96822, USA \\ ${ }^{4}$ NOAA, Southwest Fisheries Science Center, 1352 Lighthouse Ave, Pacific Grove, California 93950, USA \\ ${ }^{5}$ Institute for Computational Earth System Science, UCSB, Santa Barbara, California 93106, USA
}

\begin{abstract}
Generalized linear and generalized additive habitat models were used to predict cetacean densities for 10 species in an $818000 \mathrm{~km}^{2}$ area off California. The performance of models built with remotely sensed oceanic data was compared to that of models built with in situ measurements. Cetacean sighting data were collected by the Southwest Fisheries Science Center on 4 systematic line-transect surveys during the summer and fall of 1991, 1993, 1996, and 2001. Predictor variables included temporally dynamic, remotely sensed environmental variables (sea surface temperature and measures of its variance) and more static geographical variables (water depth, bathymetric slope, and a categorical variable representing oceanic zone). The explanatory and predictive power of different spatial and temporal resolutions of satellite data were examined and included in the models for each of the 10 species. Alternative models were built using in situ analogs for sea surface temperature and its variance. The remotely sensed and in situ models with the highest predictive ability were selected based on a pseudo-jackknife cross validation procedure. Environmental predictors included in the final models varied by species, but, for each species, overall explanatory power was similar between the remotely sensed and in situ models. Cetacean-habitat models developed using satellite data at $8 \mathrm{~d}$ temporal resolution and from 5 to $35 \mathrm{~km}$ spatial resolution were shown to have predictive ability that generally met or exceeded models developed with analogous in situ data. This suggests that the former could be an effective tool for resource managers to develop near real-time predictions of cetacean density.
\end{abstract}

KEY WORDS: Cetacean density - Habitat modeling - GAM · GLM · California Current · Remote sensing $\cdot$ Whale $\cdot$ Dolphin $\cdot$ Porpoise

Resale or republication not permitted without written consent of the publisher

\section{INTRODUCTION}

There has been a recent increase in the development of cetacean-habitat models (Redfern et al. 2006) to improve the interpretation of abundance trends (Forney 2000), aid in the development of marine protected areas (Hooker et al. 1999, Cañadas et al. 2002), and to increase the understanding of cetacean-fisheries interactions (Torres et al. 2003, Kaschner et al. 2006). Many cetacean species respond to oceanic variability by moving over scales of 10 s to 100 s of kilometers, and cetacean-habitat models can help distinguish apparent declines in abundance from movement of animals out of an area in response to changing oceanic conditions (Forney 1999). Many of the recent quantitative analyses of speciesenvironment relationships were based on cetacean sighting and oceanographic data collected simultaneously from a ship (e.g. Hedley et al. 1999, Forney 2000, 
Ferguson et al. 2006). Although some relied on satellite data to investigate cetacean-habitat associations (e.g. Waring et al. 1993, Jaquet \& Whitehead 1996, Moore et al. 2002), satellite data typically were used to augment in situ data or when equipment failure precluded the collection of along-track data (Davis et al. 1998, Baumgartner et al. 2001, Davis et al. 2002, Hamazaki 2002). However, satellite data provide synoptic spatial coverage in near real-time, and this can be an important advantage if remotely sensed data are as effective at capturing species-environment relationships as in situ data. To date, there have been no direct comparisons of cetacean habitat models based solely on in situ and solely on remotely sensed oceanic variables.

Generalized linear models (GLMs) and generalized additive models (GAMs) have been used effectively to model cetacean sighting rates (Hedley et al. 1999, Forney 2000) and cetacean density (Ferguson et al. 2006) as a function of environmental variables. Cetacean densities are typically estimated by line-transect surveys and generally result in estimates for large geographic strata (e.g. the entire United States West Coast). Habitat modeling allows predictions of cetacean densities on a finer spatial scale than traditional line-transect analyses because cetacean densities are estimated as a continuous function of habitat variables (e.g. sea surface temperature, water depth, etc.). In the present study, we developed both GAMs and GLMs to relate cetacean sighting data from shipboard surveys in the California Current region during summer and fall from 1991 to 2001 to remotely sensed environmental data. Separate sets of GAMs and GLMs were constructed using in situ data collected during the shipboard surveys or analogous satellite data. Models were built for 10 species with the greatest number of sightings: striped dolphin Stenella coeruleoalba, short-beaked common dolphin Delphinus delphis, Risso's dolphin Grampus griseus, Pacific whitesided dolphin Lagenorhynchus obliquidens, northern right whale dolphin Lissodelphis borealis, Dall's porpoise Phocoenoides dalli, sperm whale Physeter macrocephalus, fin whale Balaenoptera physalus, blue whale Balaenoptera musculus, and humpback whale Megaptera novaeangliae. Density estimates for each species were derived from the model predictions.

The objectives of the present study were: (1) to examine the most effective temporal and spatial resolutions of remotely sensed predictors for species-environment models of cetacean density, (2) to compare the performance of models built using in situ data to those built using analogous remotely sensed data, and (3) to compare cetacean densities derived from model predictions to those estimated using standard linetransect methods. This study is part of a broader suite of studies that developed habitat-based predictions of cetacean density to allow managers and users of the marine environment (e.g. the United States Navy) to improve their assessment and mitigation of anthropogenic impacts on these species (Barlow et al. 2009). If remotely sensed data are shown to be effective predictors in habitat models, this would allow cetacean densities to be estimated at finer spatial and temporal scales than using survey data alone, and near real-time predictions may be possible. Such findings would significantly improve the ability of scientists and resource managers to analyze and make decisions related to the abundance and distribution of cetacean populations in the dynamic marine environment.

\section{METHODS}

Field methods. Cetacean sighting data used to construct the predictive models were collected off California during the summer and fall (late July through early December) of 1991, 1993, 1996, and 2001 (see Barlow \& Forney 2007) using systematic ship-based line-transect methods (Buckland et al. 2001). The amount of survey effort varied among years, but transect coverage was roughly uniform throughout the study area (Fig. 1), and cetacean data collection procedures were consistent on all surveys (Kinzey et al. 2000, Barlow \& Forney 2007). In summary, 2 teams of 3 observers rotated at $2 \mathrm{~h}$ intervals among starboard observer, port observer, and data recorder positions that were located on the flying bridge of the ship. The starboard and port observers searched for animals using pedestal-mounted $25 \times 150$ binoculars, while the data recorder searched using unaided eye and $7 \times 50$ handheld binoculars. In addition to sighting data, changes in searching conditions, such as Beaufort sea state, were entered on a laptop computer connected to the ship's navigation system. When cetaceans were detected, the ship typically diverted from the transect line to estimate group size and identify the species present to the lowest taxonomic level possible. Group size was estimated by the observers and was defined to include all animals at the sighting location that were behaviorally associated with one another (traveling, foraging, milling, resting, etc.). We used only sightings made while on systematic transect lines and identified to species for building the models.

The in situ sea surface temperature (SST) data used as potential predictor variables in the comparison models were collected continuously during the line-transect surveys using a thermosalinograph with a sensor at $3 \mathrm{~m}$ depth. Details on the collection of in situ oceanic data are provided by Philbrick et al. $(1993,2003)$.

Analytical methods. Data analyses: Cetacean density predictions were derived from encounter rate and group size models using a 3-step process: (1) model development, (2) model selection, and (3) density estimation. 
Model development: GLMs and GAMs are commonly used to relate environmental data to characteristics of a species, such as distribution or abundance (see Redfern et al. 2006). We developed both GLMs and GAMs using the same datasets in order to compare model fit and predictive power statistically, and to gain ecological insight into variables and functional forms (i.e. the relationship between the response variable and the predictor variable) included in each model. Separate GLMs and GAMs were constructed to explain encounter rate and group size patterns for the 10 cetacean species.

GLMs are mathematical extensions of linear models that provide a more flexible family of regression models allowing non-constant variance structures in the data (McCullagh \& Nelder 1989). In a GLM, a function (the 'link') of the mean $(\mu)$ of the response variable is modeled as a weighted sum of predictor variables $\left(x_{1}\right.$, $x_{2}, \ldots, x_{n}$ ) plus a constant $(\alpha)$ :

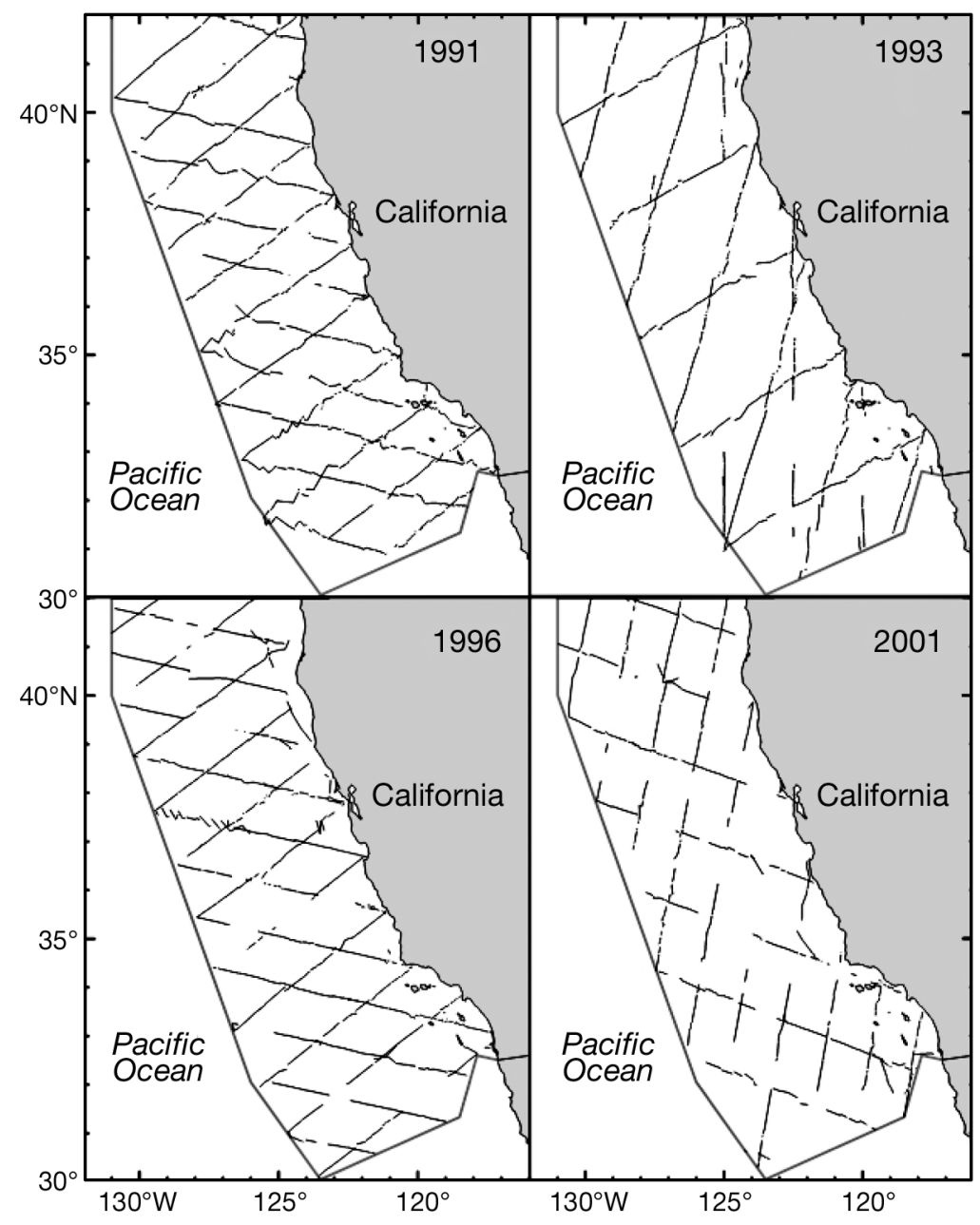

Fig. 1. Completed transects in Beaufort sea states 0 to 5 for the shipboard line-transect surveys conducted from late July through early December 1991, 1993, 1996, and 2001 off California. One degree of latitude $=111 \mathrm{~km}$

$$
\operatorname{link}\left(\mu_{i}\right)=\alpha+\sum_{i=1}^{n} \beta_{i} x_{i}
$$

Each of the predictor variables in GLMs may be transformed to represent non-linear effects according to specified parametric functions (e.g. polynomial, exponential, logarithmic).

GAMs are non-parametric extensions of GLMs, sharing many of the same statistical properties (e.g. additivity) without constraining the predictor variables to enter the model as a particular parametric form. As with GLMs, a GAM is created using a link function defining the relationship between the mean of the response variable and the functions, $f(x)$, of the predictor variables:

$$
\operatorname{link}\left(\mu_{i}\right)=\alpha+\sum_{i=1}^{n} f_{i}\left(x_{i}\right)
$$

The components $f_{i}\left(x_{i}\right)$ can include non-parametric smooth functions (splines) of the predictor variables, allowing GAMs to be much more flexible than GLMs.

Separate encounter rate and group size GLMs and GAMs were built using the step.gam function in the statistical software package S-PLUS (Professional Edition Version 6.0.2, Release 1 for Windows, Insightful Corp., 2001). We employed the stepwise forward/backward variable selection procedure developed by Ferguson et al. (2006), in which the stepwise selection process occurred twice for each model in order to improve the dispersion parameter estimate used to assess the final model. Variables were tested for inclusion as linear terms and polynomials or smoothing splines having up to $3 \mathrm{de}$ grees of freedom. Models built with $>3$ degrees of freedom can add unrealistic complexity to the functions and tend to be difficult to interpret ecologically (Hastie \& Tibshirani 1990, Forney 2000, Ferguson et al. 2006). Akaike's Information Criterion (AIC; Akaike 1973) was initially used in step.gam as the basis for selecting among potential combinations of predictor variables and varying degrees of freedom. Therefore, all the potential predictor variables with all combinations of functions (e.g. linear, polynomial, exponential, logarithmic for the GLMs, and linear and spline fits for the GAMs) each at several orders $(0,1,2$, and 3) were tested, and the best combination was selected by AIC criteria. Models were constructed separately for datasets that excluded 1 of the 4 survey years; however, the warmest year, 1993, 
was included in all model combinations to capture the broadest possible range of interannual variability in oceanic conditions.

In order to create samples for modeling, cetacean survey data from the 4 shipboard surveys were separated into transect segments of approximately $5 \mathrm{~km}$ length, corresponding to the finest resolution of satellite data used for this analysis $(5.55 \mathrm{~km})$. The lengths of continuous sections of survey effort were not, however, exact multiples of $5 \mathrm{~km}$, and there was generally an 'extra' distance of from 0.1 to $4.9 \mathrm{~km}$. If this extra distance was $<2.5 \mathrm{~km}$ long, it was included with a randomly chosen $5 \mathrm{~km}$ segment, increasing the length of that segment. If the extra distance was $\geq 2.5 \mathrm{~km}$, a separate segment of from 2.5 to $4.9 \mathrm{~km}$ was created at a randomly placed cut-point along the effort section. If the entire continuous effort section was $<5 \mathrm{~km}$, it was treated as a separate segment regardless of length. The resulting dataset contained a total of 7264 segments, with the majority (73\%) equal to the target length of $5 \mathrm{~km}, 23 \%$ of length from 2.5 to $5 \mathrm{~km}$ or 5 to $7.5 \mathrm{~km}$, and a small portion ( $4 \%$ ) of $<2.5 \mathrm{~km}$ long.

Encounter rate models were built with the number of sightings per segment as the response variable. To account for the varying length of our segments, segment length was included as an offset term in the models to standardize each sample for effort. In order to maximize sample size for both the remotely sensed and in situ models, encounter rate models were built with all the segments available for the respective SST data. Encounter rates are count data with a large number of zeroes and are expected to follow an over-dispersed Poisson distribution. Therefore, quasi-Poisson encounter rate models were built using a log-link function and a quasi-likelihood error distribution with the variance proportional to the mean (McCullagh \& Nelder 1989). Group size models were built using only those segments that contained sightings. Group size models were assumed to follow a log-normal distribution (Ferguson et al. 2006) and therefore were built using the natural logarithm of group size as the response variable with an identity link function and a Gaussian error distribution (McCullagh \& Nelder 1989).

Model selection: The initial stepwise model-development process that excluded $1 \mathrm{yr}$ at a time yielded 3 potential encounter rate GLMs and GAMs (i.e. a 'no1991 model', a 'no-1996 model', and a 'no-2001 model') and 3 potential group size GLMs and GAMs for each species and each of the 2 data types (i.e. satellite and in situ). The 'best' encounter rate and group size GLMs and GAMs were then selected based on a cross validation process (Hastie \& Tibshirani 1990) that we refer to as a 'pseudo-jackknife,' whereby each model of the 3 selected in the first phase was re-fit to the remaining combinations of $(n-1)$-year datasets and its predictive ability was assessed by cross validation. The re-fitting process does not change the variables or associated functional forms of the models selected during the initial stepwise procedure, but it forces these models on each of the remaining $(n-1)$-year datasets. The model with the lowest sum of average squared prediction error (ASPE; Hastie \& Tibshirani 1990) values was selected as the best overall model (in cases with ties, the model with the lower ASPE for the novel data was selected). For the encounter rate models, ASPE calculations were based on Anscombe residuals to account for the quasi-likelihood error distribution (McCullagh \& Nelder 1989).

The model selected based on the pseudo-jackknife process was then re-fit to a smaller dataset for which both remotely sensed and in situ SST data were available for all segments, and the multi-year ASPE was calculated for each encounter rate and group size model. For each species, the remotely sensed and in situ GAM or GLM with the lowest ASPE value was carried forward as the final predictive model. If models had identical ASPEs, but different predictor variables, then the model with the greatest explained deviance (McCullagh \& Nelder 1989) was selected.

Density estimation: Density (number of animals per square kilometer) for each species was estimated by incorporating the final encounter rate and group size model results into the standard line-transect equation (Buckland et al. 2001):

$$
D=\left(\frac{n}{L}\right) \cdot s \cdot \frac{1}{2 \cdot \mathrm{ESW} \cdot g(0)}
$$

where $n / L$ is the predicted encounter rate (number of sightings per unit length of trackline in kilometers), $s$ is the predicted group size, ESW is the effective strip half-width in kilometers, or $1 / f(0)$, where $f(0)$ is the probability density function evaluated at zero perpendicular distance (i.e. on the trackline), and $g(0)$ is the probability of detecting a group of animals on the trackline. A ratio estimator (Finney 1941, Smith 1993) was used to correct for the bias resulting from backtransforming the logarithmic values produced by the group size models.

We relied on published values of $f(0)$ (or ESW) and $g(0)$ for each species as estimated from the same survey data (Barlow 2003) for the same range of Beaufort sea state conditions ( 0 to 5 ). The only exception was for Dall's porpoise, for which the published $f(0)$ and $g(0)$ were derived for Beaufort sea state conditions of from 0 to 2. Survey effort in these Beaufort conditions was not distributed uniformly across the study area (see Fig. 2 in Barlow \& Forney 2007), and models built using only segments with these Beaufort conditions would not have captured the full range of habitat types for Dall's porpoise in the study area. Therefore, we ini- 
tially constructed the Dall's porpoise models using the full range of sea state conditions (0 to 5). To prevent bias, however, the final density predictions were based on the average Beaufort sea state for all segments in sea states of from 0 to 2 . For many species, published $f(0)$ and $g(0)$ values were stratified by group size, and, therefore, we weighted $f(0)$ and $g(0)$ values based on the number of small and large groups observed during the surveys for our density calculations.

Paired encounter rate and group size predictions from each data source (satellite/in situ) were used to estimate segment-specific density by species. The model-based average study-area density (prior to interpolation) was compared to the density estimate derived by standard line-transect analyses without environmental data (hereafter called 'standard density estimates'). Segment-specific density estimates from the models were also interpolated to the entire study area using Surfer 8.0 (Version 8, Golden Software). It was necessary to interpolate the segment-specific density predictions because predictions from the models built with in situ data were available only for the surveyed segments; in order to provide a meaningful comparison, we also interpolated predictions from the models built with remotely sensed data. Interpolation grids were created at a resolution of $25 \mathrm{~km}$, using inverse distance weighting to the second power. This weighting method gives points closer to each grid node greater influence than those farther away. All data within a search radius of 2 degrees latitude $(222 \mathrm{~km})$ were used for interpolation, because transect spacing ranged from 150 to $230 \mathrm{~km}$ during the 4 different survey years, and contouring results were more robust when data from $>1$ transect line were included. Sightings were plotted on the grids to provide a means for visually evaluating the models' predictive capability.

Grids were created for each of the individual survey years, and the individual grid cells were averaged across all years to calculate mean species density and its variance. To eliminate occasional over-specification ('bull's eye' effects) in the final average prediction grid, a $5 \times 5$ pixel moving average filter with equal weights was applied to the entire grid. The complete gridding process thus provided smoothed multi-year average cetacean densities, taking into account both the varying oceanographic conditions and different levels of sampling coverage achieved during the SWFSC cetacean surveys. Standard errors were calculated from the yearly grid cell values using standard formulae. Because interannual variability is the largest source of uncertainty in these models, variance in the overall study-area density was calculated from the yearly predictions for all 3 estimation methods (line-transect, in situ models, and remotely sensed models).
Habitat predictor variables: Predictor variables included SST, the standard deviation (SD) of SST, oceanic zone, water depth, bathymetric slope, and Beaufort sea state. We included SD(SST) to serve as a proxy for frontal regions; dynamic oceanic processes such as upwelling, fronts, and eddies often result in surface SST gradients between colder upwelled water and warmer surface waters. These oceanic processes can serve to increase biological production and aggregate prey (Mann \& Lazier 2006). Chlorophyll could not be included in the models because remotely sensed chlorophyll data were not available during the period from 1991 to 1996. SST and SD(SST) were the only variables that differed between the remotely sensed and in situ models. Oceanic zone was included as a ranked categorical variable defined roughly by water depth: shelf $=$ waters from the coast to $200 \mathrm{~m}$ deep, slope = waters between 200 and $2000 \mathrm{~m}$ deep, and abyssal plain = waters deeper than $2000 \mathrm{~m}$. Water depth in each segment was obtained from the ETOPO2 2 min global relief data (US Department of Commerce, NOAA, NGDC 2006), re-gridded to match the pixel resolution used for this analysis. Bottom slope was calculated as the magnitude of the bathymetry gradient using the gradient operator tool in GMT (Generic Mapping Tools; Wessel \& Smith 1998). Individual depth and bottom slope values estimated at the midpoint of each segment were retrieved using the 'sample' tool in ArcGIS (Version 9.2, ESRI). Beaufort sea state affects the probability of detecting animals (Barlow et al. 2001), and an average sea state value within the segment was included as a continuous predictor variable in our models in order to account for sighting conditions. Because the probability of detection decreases dramatically in sea states exceeding Beaufort 5 (Barlow et al. 2001), the line-transect sighting parameter estimates derived from these survey data were based on effort in Beaufort sea states from 0 to 5 (Barlow 2003). Therefore, for consistency, segments with average sea state values exceeding Beaufort 5 (a total of 83 segments) were eliminated from this analysis.

Remotely sensed environmental data: Mean SST values (National Oceanic and Atmospheric Administration/National Environmental Satellite, Data, and Information Service/Pathfinder v5) were obtained for 3 temporal resolutions $(1,8$, and $30 \mathrm{~d}$ composites of binned, arithmetic means centered on the day of the survey) at the finest available pixel resolution (0.05 degrees or approximately $5.55 \mathrm{~km}$ ) to initially compare sample size and, data permitting, compare predictive power. Mean values of SST also were obtained for 6 spatial resolutions: 1 pixel $\left(30.8 \mathrm{~km}^{2}\right), 2 \times$ 2 pixel $\left(123.2 \mathrm{~km}^{2}\right), 3 \times 3$ pixel $\left(277.2 \mathrm{~km}^{2}\right), 4 \times 4$ pixel $\left(482.8 \mathrm{~km}^{2}\right), 5 \times 5$ pixel $\left(770.1 \mathrm{~km}^{2}\right)$, and $6 \times 6$ pixel $\left(1109 \mathrm{~km}^{2}\right)$ regions surrounding the segment midpoint. 
$\mathrm{SD}(\mathrm{SST})$ values were calculated for the 5 spatial resolutions that included $>1$ pixel.

We initially calculated correlation coefficients between all possible combinations of the 6 spatial resolutions of SST data and found them highly correlated; the lowest $R^{2}$ value of $0.98(p<0.0000)$ resulted from a regression of SST values extracted from the finest ( 1 pixel) to the coarsest (36 pixel average) resolution considered in the present analysis. To select which spatial resolution of SST to include as the best predictor variable, we built separate encounter rate and group size GAMs and GLMs for each species including a single SST resolution at a time and holding sample size constant. We did not include all resolutions in any single model-building process because regression models have difficulty distinguishing between highly correlated variables. Therefore, for the scale analysis, we restricted the models to 2 variables: 1 resolution of SST and Beaufort sea state. Models were constructed separately for datasets that excluded 1 of the 4 survey years, respectively, and then predictions were made on the year left out of the model building process to yield an ASPE. ASPE values were then summed across years for each of the 6 spatial resolutions. In cases where different spatial resolutions minimized ASPEs for GLMs and GAMs, we selected the resolution that minimized the sum of the GLM and GAM ASPE values. The greatest spatial resolution that yielded an ASPE sum within $5 \%$ of the best predictive model was selected as the best predictive model, because larger spatial resolutions resulted in fewer data lost due to cloud cover. The $5 \%$ margin was selected arbitrarily because ASPE cannot be estimated without error and varies with the specific samples included in the dataset. We used the same procedure to select spatial resolutions of $\mathrm{SD}$ (SST).

Following selection of the most appropriate temporal and spatial resolution of SST data, all encounter rate and group size models were built with the full suite of potential predictor variables: SST (at the speciesspecific spatial resolution), SD of SST (at the speciesspecific spatial resolution), zone, depth, bathymetric slope, and Beaufort sea state. All of the SST data used for modeling were matched specifically to the survey date for each of the 4 years.

In situ environmental data: SST data included in the in situ analysis were limited to measurements collected while on the systematic transect lines. We obtained average SST and SD(SST) estimates from all measurements within $2.775,5.550,8.325,11.100,13.875$, and $16.650 \mathrm{~km}$ of the segment midpoints to match the spatial resolution of our satellite data (i.e. 5.55, 11.10, 16.65, 22.20, 27.75, and $33.30 \mathrm{~km}$ ). For the models built using in situ data, we used the species-specific spatial resolutions selected for the satellite data analysis to ensure that the comparison was based on the most comparable predictor variables. Despite our attempt to match spatial resolutions between the remotely sensed and in situ $\mathrm{SD}(\mathrm{SST})$ measures, there are inherent differences in the dimensions over which SST variation was calculated: in situ variation was calculated from along-track SST measures, reflecting a roughly linear change (1 dimensional variation), while remotely sensed measures reflect 2 dimensional variation at the various spatial scales. We also compared the satellite-derived and in situ measures of SST and $\mathrm{SD}(\mathrm{SST})$ by calculating correlation coefficients for each pair of values for each of the spatial resolutions.

\section{RESULTS}

Barlow \& Forney (2007) provide information on the search effort, number of species sighted, and associated line-transect abundance estimates for the 1991 to 2001 shipboard surveys. The 10 species we used for model development were selected to maximize sample size and provide a range of known or expected habitat preferences, group size dynamics, and presence in the study area (i.e. year-round residents vs. seasonal visitors). They included warm-temperate/tropical species (striped dolphin, short-beaked common dolphin), cold-temperate species (Pacific white-sided dolphin, northern right whale dolphin, Dall's porpoise), a cosmopolitan species (Risso's dolphin), baleen whales present year-round (fin whale) and only during summer feeding periods (blue whale, humpback whale), as well a large toothed whale species known to occur in highly variable group sizes (sperm whale).

\section{Temporal and spatial resolution of satellite-derived SST data}

The encounter rate and group size models built using each of the 3 temporal resolutions $(1,8$, and $30 \mathrm{~d}$ composites at $5.55 \mathrm{~km}\left[30.8 \mathrm{~km}^{2}\right]$ spatial resolution) of satellitederived SST data enabled a comparison of sample size and predictive power. Due to persistent fog off the California coast, $1 \mathrm{~d}$ composites lacked sufficient data to build robust models (e.g. SST data at this resolution were available for $<15 \%$ of our 2001 dataset). The $30 \mathrm{~d}$ SST composites had good explanatory ability as indicated by the percent of explained deviance for each of the (n-1)year models, which often exceeded that of models built with $8 \mathrm{~d}$ composite SST data. However, predictive ability, as evaluated by each ( $\mathrm{n}-1)$-year model's predictions for the year left out of model building, was poor at the $30 \mathrm{~d}$ resolution. A correlation analysis showed high correlation between the 1 and $8 \mathrm{~d}$ SST values $\left(\mathrm{R}^{2}=0.96\right)$, indicating that the $8 \mathrm{~d}$ composites provided adequate cover- 
Table 1. Summary of spatial resolutions of satellite-derived sea surface temperature (SST) and the SD of SST that had the greatest predictive ability for encounter rate and group size models. Values presented are the number of pixels included in the resolution cell. The spatial resolutions tested included 1, 4, 9, 16, 25, and 36 pixel boxes, corresponding to 5.55-33.3 km boxes (i.e. $30.8-1108.9 \mathrm{~km}^{2}$ )

\begin{tabular}{|c|c|c|c|c|}
\hline \multirow{3}{*}{ Species } & \multirow{2}{*}{\multicolumn{2}{|c|}{ - Encounter rate - }} & \multirow{2}{*}{\multicolumn{2}{|c|}{ - Group size }} \\
\hline & & & & \\
\hline & SST & $\mathrm{SD}(\mathrm{SST})$ & SST & $\mathrm{SD}(\mathrm{SST})$ \\
\hline Striped dolphin Stenella coeruleoalba & 36 & 25 & 36 & 16 \\
\hline Short-beaked common dolphin Delphinus delphis & 36 & 25 & 36 & 25 \\
\hline Risso's dolphin Grampus griseus & 9 & 16 & 36 & 16 \\
\hline Pacific white-sided dolphin Lagenorhynchus obliquidens & 36 & 9 & 36 & 36 \\
\hline Northern right whale dolphin Lissodelphis borealis & 36 & 36 & 36 & 25 \\
\hline Dall's porpoise Phocoenoides dalli & 25 & 36 & 36 & 36 \\
\hline Sperm whale Physeter macrocephalus & 36 & 36 & 36 & 36 \\
\hline Fin whale Balaenoptera physalus & 36 & 9 & 36 & 9 \\
\hline Blue whale Balaenoptera musculus & 36 & 25 & 36 & 36 \\
\hline Humpback whale Megaptera novaeangliae & 36 & 36 & 36 & 4 \\
\hline
\end{tabular}

age while maintaining fairly consistent representation of average conditions on the day of the survey. Based on this evaluation, we selected $8 d$ running average SST composites centered on the date of each survey segment.

Of the total 7264 segments in our dataset, >35\% were eliminated due to missing satellite data at the finest spatial resolution (single pixel) while $<17 \%$ were eliminated at the coarsest spatial resolution (maximum of 36 pixels). For most species, predictive ability was higher at coarser spatial resolutions (Table 1).

$\mathrm{SD}(\mathrm{SST})$ values for the 5 potential spatial resolutions were not as highly correlated as SST values $\left(\mathrm{R}^{2}\right.$ values ranged from 0.20 to 0.82 ). For a few of the species such as fin whale, the 'best' SD(SST) spatial resolution was much finer than the 'best' SST spatial resolution (Table 1).

The final datasets for each species consisted of the number of segments with available SST data for each species-specific spatial resolution; for all species combined, approximately $20 \%$ more sightings were available for building the in situ models than for models based on remotely sensed SST (Table 2). Remotely sensed and in situ SST data were highly correlated across all spatial scales. In contrast, correlations between SD (SST) values were weak and increased slightly with increasing spatial scale (Table 3). Remotely sensed SST values tended to be slightly lower than those measured in situ (Table 3).

\section{Encounter rate and group size models}

Models built using remotely sensed or in situ data generally included the same variables with similar functional relationships between predictor and response variables, particularly for 'key' predictor variables (those having the greatest effect on the mean response) (Table 4 and Figs. $2 \& 3$ ). Variables that had

Table 2. Number of sightings and segments (samples) in Beaufort sea states 0 to 5 from the Southwest Fisheries Science Center's 1991, 1993, 1996, and 2001 surveys of California waters (survey) and the number of sightings and segments with in situ and satellite SST data at the finest spatial resolution used in the final encounter rate and group size models for each species. Shared: the number of sightings for which both in situ and satellite data were available. Taxonomic names, see Table 1

\begin{tabular}{|c|c|c|c|c|c|}
\hline \multirow[t]{2}{*}{ Species } & \multirow[t]{2}{*}{ Samples } & \multicolumn{4}{|c|}{ — Total number } \\
\hline & & Survey & In situ & Satellite & Shared \\
\hline Striped dolphin & $\begin{array}{l}\text { Sightings } \\
\text { Segments }\end{array}$ & $\begin{array}{c}61 \\
7264\end{array}$ & $\begin{array}{c}60 \\
7150\end{array}$ & $\begin{array}{c}50 \\
5832\end{array}$ & $\begin{array}{c}49 \\
5755\end{array}$ \\
\hline Short-beaked common dolphin & $\begin{array}{l}\text { Sightings } \\
\text { Segments }\end{array}$ & $\begin{array}{c}397 \\
7264\end{array}$ & $\begin{array}{c}394 \\
7158\end{array}$ & $\begin{array}{c}309 \\
6005\end{array}$ & $\begin{array}{c}306 \\
5928\end{array}$ \\
\hline Risso's dolphin & $\begin{array}{l}\text { Sightings } \\
\text { Segments }\end{array}$ & $\begin{array}{c}80 \\
7264\end{array}$ & $\begin{array}{c}79 \\
7166\end{array}$ & $\begin{array}{c}71 \\
6132\end{array}$ & $\begin{array}{c}70 \\
6054\end{array}$ \\
\hline Pacific white-sided dolphin & $\begin{array}{l}\text { Sightings } \\
\text { Segments }\end{array}$ & $\begin{array}{c}41 \\
7264\end{array}$ & $\begin{array}{c}41 \\
7134\end{array}$ & $\begin{array}{c}25 \\
5583\end{array}$ & $\begin{array}{c}25 \\
5500\end{array}$ \\
\hline Northern right whale dolphin & $\begin{array}{l}\text { Sightings } \\
\text { Segments }\end{array}$ & $\begin{array}{c}52 \\
7264\end{array}$ & $\begin{array}{c}52 \\
7166\end{array}$ & $\begin{array}{c}40 \\
6132\end{array}$ & $\begin{array}{c}40 \\
5928\end{array}$ \\
\hline Dall's porpoise & $\begin{array}{l}\text { Sightings } \\
\text { Segments }\end{array}$ & $\begin{array}{c}268 \\
7264\end{array}$ & $\begin{array}{c}268 \\
7158\end{array}$ & $\begin{array}{c}179 \\
6005\end{array}$ & $\begin{array}{c}179 \\
5928\end{array}$ \\
\hline Sperm whale & $\begin{array}{l}\text { Sightings } \\
\text { Segments }\end{array}$ & $\begin{array}{c}49 \\
7264\end{array}$ & $\begin{array}{c}49 \\
7166\end{array}$ & $\begin{array}{c}37 \\
6132\end{array}$ & $\begin{array}{c}37 \\
6054\end{array}$ \\
\hline Fin whale & $\begin{array}{l}\text { Sightings } \\
\text { Segments }\end{array}$ & $\begin{array}{c}142 \\
7264\end{array}$ & $\begin{array}{c}134 \\
7134\end{array}$ & $\begin{array}{c}127 \\
5583\end{array}$ & $\begin{array}{c}120 \\
5500\end{array}$ \\
\hline Blue whale & $\begin{array}{l}\text { Sightings } \\
\text { Segments }\end{array}$ & $\begin{array}{c}197 \\
7264\end{array}$ & $\begin{array}{c}192 \\
7166\end{array}$ & $\begin{array}{c}166 \\
6132\end{array}$ & $\begin{array}{c}161 \\
6054\end{array}$ \\
\hline Humpback whale & $\begin{array}{l}\text { Sightings } \\
\text { Segments }\end{array}$ & $\begin{array}{c}95 \\
7264\end{array}$ & $\begin{array}{c}95 \\
7166\end{array}$ & $\begin{array}{c}84 \\
6132\end{array}$ & $\begin{array}{c}84 \\
6054\end{array}$ \\
\hline Total number of sightings & & 1382 & 1364 & 1088 & 1071 \\
\hline
\end{tabular}


Table 3. Correlations ( $\mathrm{R}^{2}$ values) between satellite and in situ sea surface temperature (SST) and SD(SST) at each of the spatial resolutions considered in the present study. Spatial resolution for the in situ data reflects linear distances that match that of the satellite data (e.g. 1 pixel is approximately equal to a $5.55 \mathrm{~km}$ box). SST bias: mean (satellite SST - in situ SST). SD(SST) is not applicable (na) to the $5.55 \mathrm{~km}$ resolution because it includes only 1 pixel

\begin{tabular}{|lccccc|}
\hline $\begin{array}{l}\text { Spatial resolution } \\
\text { (satellite data) }\end{array}$ & $\begin{array}{l}\text { No. of } \\
\text { pixels }\end{array}$ & $\begin{array}{c}\text { Spatial resolution } \\
\text { (in situ data) }\end{array}$ & $\begin{array}{c}\text { SST } \\
\left(\mathrm{R}^{2}\right)\end{array}$ & SST bias & $\begin{array}{c}\text { SD(SST) } \\
\left(\mathrm{R}^{2}\right)\end{array}$ \\
\hline $5.55 \mathrm{~km} \times 5.55 \mathrm{~km}$ & 1 & $5.55 \mathrm{~km}$ & 0.81 & -0.023 & $\mathrm{NA}$ \\
$11.10 \mathrm{~km} \times 11.10 \mathrm{~km}$ & 4 & $11.10 \mathrm{~km}$ & 0.82 & -0.038 & 0.01 \\
$16.65 \mathrm{~km} \times 16.65 \mathrm{~km}$ & 9 & $16.65 \mathrm{~km}$ & 0.82 & -0.041 & 0.04 \\
$22.20 \mathrm{~km} \times 22.20 \mathrm{~km}$ & 16 & $22.20 \mathrm{~km}$ & 0.83 & -0.046 & 0.08 \\
$27.75 \mathrm{~km} \times 27.75 \mathrm{~km}$ & 25 & $27.75 \mathrm{~km}$ & 0.83 & -0.051 & 0.11 \\
$33.30 \mathrm{~km} \times 33.30 \mathrm{~km}$ & 36 & $33.30 \mathrm{~km}$ & 0.83 & -0.056 & 0.14 \\
\hline
\end{tabular}

the greatest effect on encounter rate across species were SST and depth (Table 4 a and Figs. 2 \& 3). Beaufort sea state was also included in the majority of encounter rate models, confirming this variable's effect on detection probability. In general, fewer variables were included in the group size models (Table $4 \mathrm{~b}$ ).

The percentage of deviance explained by the final encounter rate models built with remotely sensed data ranged from 5\% (short-beaked common dolphin) to $39 \%$ (Dall's porpoise) (Table 5). Corresponding explained deviance for the final encounter rate models built with in situ data ranged from $3 \%$ (sperm whale) to $35 \%$ (Dall's porpoise). The explained deviance of group size models built with remotely sensed data ranged from 3\% (Dall's porpoise) to 54\% (Pacific white-sided dolphin) and from $4 \%$ (fin whale) to $52 \%$ (Pacific white-sided dolphin) for the group size models built with in situ data (Table 5). Model performance as indicated by ASPE differed among species, but neither model type (remotely sensed/in situ) consistently performed better overall (Table 5).

The overall density of each species within the study area was estimated using the weighted $f(0)$ and $g(0)$ estimates shown in Table 6. For most of the species, particularly those with the greatest number of sightings, density estimates were similar for both the satellite and in situ models (Table 7). However, for 1 species with $<30$ sightings (Pacific white-sided dolphin), density estimates differed by $>30 \%$ and the in situ model was $>35 \%$ different than the standard density estimate derived from the survey data (Table 7). For this species, there were also greater differences in the numbers and types of predictor variables included in the final encounter rate models (Table $4 \mathrm{a}$ and Fig. 3). Smoothed density plots for Pacific white-sided dolphin show obvious dissimilarities, while those with similar predicted/ standard density ratios (e.g. short-beaked common dolphin, Dall's porpoise, humpback whale) are almost indistinguishable (Fig. 4).

\section{DISCUSSION}

\section{Spatial resolutions of SST and SD(SST)}

For all species, the encounter rate and group size models showed similar functional relationships between SST and the response variables across spatial resolution. However, for the majority of species, the greatest predictive ability was observed for the coarsest SST resolution (36 pixels or approximately 1109 $\mathrm{km}^{2}$ ). There is a lack of precision in both the sighting and satellite positions that may be better represented by coarser spatial resolutions. In addition, there is a temporal offset between the ship survey and satellite data acquisition. In the study area, upwelled water is moved offshore by Ekman transport and south by the California Current, which has a surface velocity of approximately $9 \mathrm{~cm} \mathrm{~s}^{-1}$ (Lynn \& Simpson 1987). The spatial displacement of surface water is thus on the order of $10 \mathrm{~km} \mathrm{~d}^{-1}$. A particle of water could travel $40 \mathrm{~km}$ over the temporal resolution ( $8 \mathrm{~d}$ composites centered on the day of the survey) used in the present study.

Although some cetaceans are known to track finescale features (Etnoyer et al. 2006, Doniol-Valcroze et al. 2007), others appear to respond to broad-scale oceanographic patterns, essentially filtering out finer resolution 'noise'. The influence of scale on the identification and interpretation of cetacean-habitat relationships is recognized as an important topic, and has been the focus of recent research efforts (e.g. Redfern et al. 2008). The California Current is dominated by smaller, mesoscale features, but our results suggest it may be worth investigating larger spatial resolutions in future analyses.

The predictive ability of different spatial resolutions of satellite-derived SD(SST), which we used as a proxy for frontal regions, was more variable than that of SST. For many species, the best $\mathrm{SD}(\mathrm{SST})$ spatial resolution was among the finer resolutions considered in the present study (Table 1), perhaps reflecting the importance of localized upwelling events or small-scale frontal features.

\section{Predictor variables}

The basic functional form of most of the predictor variables was similar between models built with remotely sensed and in situ data. This was not surprising for SST given the correlation between remotely sensed and in situ values. These results indicate that remotely sensed measures of SST can be used effectively in place of in situ measures. 
The only variable that exhibited differences between the models built with remotely sensed and in situ data was $\mathrm{SD}(\mathrm{SST})$. This difference is likely due to the different dimensions over which SST variation was calculated: in situ variation was calculated from alongtrack SST measures, reflecting a roughly linear change (1 dimensional variation), while remotely sensed measures reflect 2 dimensional variation at the various spatial scales. This difference was most apparent in the group size models for the fin whale, where the functional form of $\mathrm{SD}(\mathrm{SST})$ at the $16.6 \mathrm{~km}$ spatial resolution differed between in situ and remotely sensed models. The in situ model showed group size increasing as SST variation decreases. In contrast, the

Table 4. Comparison of the variables included in the final (a) encounter rate and (b) group size models built with satellite and in situ data. Final model type (Generalized Additive Model [GAM] or Generalized Linear Model [GLM]) reflects the model with the lowest average squared prediction error (ASPE; 'both' indicates that the GAM and GLM had the same ASPE and included identical terms). Linear fits are represented by 'L1'. Smoothing splines (GAMs) are represented by 'S\#', and polynomial fits (GLMs) are represented by 'P\#', where \# indicates the associated degrees of freedom. Note that 'zone' is a categorical variable (' $\mathrm{C}$ ') that requires 2 degrees of freedom. A '-' indicates that the variable was not included in the model. For those species where the remotely sensed and in situ models included different predictor variables and/or degrees of freedom, the variable codes (e.g. 'S\#', 'P\#', etc.) are shown in bold. Taxonomic names, see Table 1

\begin{tabular}{|c|c|c|c|c|c|c|c|c|}
\hline \multirow{2}{*}{ Species } & \multirow{2}{*}{ Data source } & \multirow[t]{2}{*}{ Model } & \multicolumn{6}{|c|}{ - Predictor variables } \\
\hline & & & Zone & Depth & Slope & SST & $\mathrm{SD}(\mathrm{SST})$ & Beaufort \\
\hline \multicolumn{9}{|l|}{ (a) Encounter rate models } \\
\hline \multirow[t]{2}{*}{ Striped dolphin } & Satellite & GLM & - & P2 & - & P2 & P2 & L1 \\
\hline & In situ & Both & - & L1 & - & - & L1 & L1 \\
\hline \multirow[t]{2}{*}{ Short-beaked common dolphin } & Satellite & GAM & $\mathrm{C} 2$ & - & - & S3 & - & L1 \\
\hline & In situ & GAM & $\mathrm{C} 2$ & $\mathbf{S 2}$ & - & S3 & - & L1 \\
\hline \multirow[t]{2}{*}{ Risso's dolphin } & Satellite & Both & - & L1 & - & - & - & - \\
\hline & In situ & Both & - & L1 & - & - & - & - \\
\hline \multirow[t]{2}{*}{ Pacific white-sided dolphin } & Satellite & GAM & $\mathrm{C} 2$ & S3 & - & S3 & S3 & - \\
\hline & In situ & GAM & $\mathrm{C} 2$ & - & - & $\mathbf{S 2}$ & - & - \\
\hline \multirow{2}{*}{ Northern right whale dolphin } & Satellite & GLM & $\mathrm{C} 2$ & - & - & P3 & - & P3 \\
\hline & In situ & GLM & $\mathrm{C} 2$ & - & - & P3 & - & P3 \\
\hline \multirow{2}{*}{ Dall's porpoise } & Satellite & GLM & C2 & P2 & P3 & P3 & P2 & P3 \\
\hline & In situ & GLM & - & P2 & - & P3 & $\mathrm{P} 2$ & P3 \\
\hline \multirow[t]{2}{*}{ Sperm whale } & Satellite & GLM & - & P2 & - & L1 & L1 & L1 \\
\hline & In situ & GAM & C2 & - & - & - & - & S3 \\
\hline \multirow[t]{2}{*}{ Fin whale } & Satellite & GLM & $\mathrm{C} 2$ & - & - & P2 & - & - \\
\hline & In situ & GLM & $\mathrm{C} 2$ & - & - & $\mathrm{P} 2$ & - & - \\
\hline \multirow[t]{2}{*}{ Blue whale } & Satellite & GAM & - & L1 & - & - & - & S3 \\
\hline & In situ & GAM & C2 & - & - & - & - & S3 \\
\hline \multirow[t]{2}{*}{ Humpback whale } & Satellite & GAM & $\mathrm{C} 2$ & L1 & - & S3 & - & - \\
\hline & In situ & GAM & $\mathrm{C} 2$ & L1 & - & S3 & S3 & L1 \\
\hline \multicolumn{9}{|l|}{ (b) Group size models } \\
\hline \multirow[t]{2}{*}{ Striped dolphin } & Satellite & Both & - & - & - & L1 & - & - \\
\hline & In situ & Both & - & - & - & L1 & - & - \\
\hline \multirow[t]{2}{*}{ Short-beaked common dolphin } & Satellite & Both & - & - & - & L1 & - & L1 \\
\hline & In situ & Both & - & - & - & L1 & - & - \\
\hline \multirow[t]{2}{*}{ Risso's dolphin } & Satellite & Both & - & - & - & L1 & - & - \\
\hline & In situ & Both & - & - & - & L1 & - & - \\
\hline \multirow[t]{2}{*}{ Pacific white-sided dolphin } & Satellite & GAM & $\mathrm{C} 2$ & - & - & - & $\mathbf{S} 2$ & L1 \\
\hline & In situ & Both & $\mathrm{C} 2$ & - & - & - & L1 & L1 \\
\hline \multirow[t]{2}{*}{ Northern right whale dolphin } & Satellite & Both & - & - & - & L1 & - & L1 \\
\hline & In situ & Both & $\mathrm{C} 2$ & - & - & L1 & - & - \\
\hline \multirow[t]{2}{*}{ Dall's porpoise } & Satellite & Both & - & - & L1 & - & - & L1 \\
\hline & In situ & GLM & - & P2 & - & - & L1 & L1 \\
\hline \multirow[t]{2}{*}{ Sperm whale } & Satellite & Both & C2 & - & - & - & - & - \\
\hline & In situ & Both & - & L1 & - & L1 & L1 & - \\
\hline Fin whale & Satellite & GLM & - & - & - & - & P3 & - \\
\hline & In situ & GAM & C2 & - & - & - & S2 & - \\
\hline Blue whale & Satellite & Both & C2 & - & L1 & - & - & - \\
\hline & In situ & GLM & - & - & - & P3 & - & - \\
\hline Humpback whale & Satellite & GAM & - & S3 & - & - & - & - \\
\hline & In situ & GAM & $\mathrm{C} 2$ & $\mathbf{S} 2$ & - & - & - & - \\
\hline
\end{tabular}




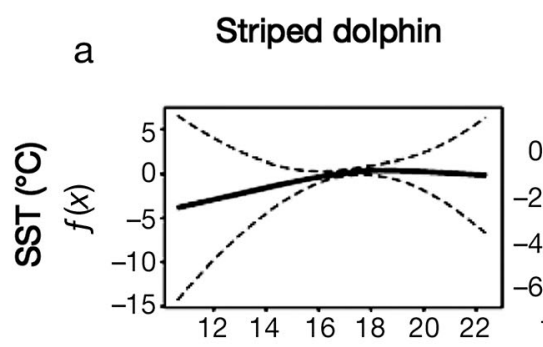

\section{Short-beaked common dolphin}
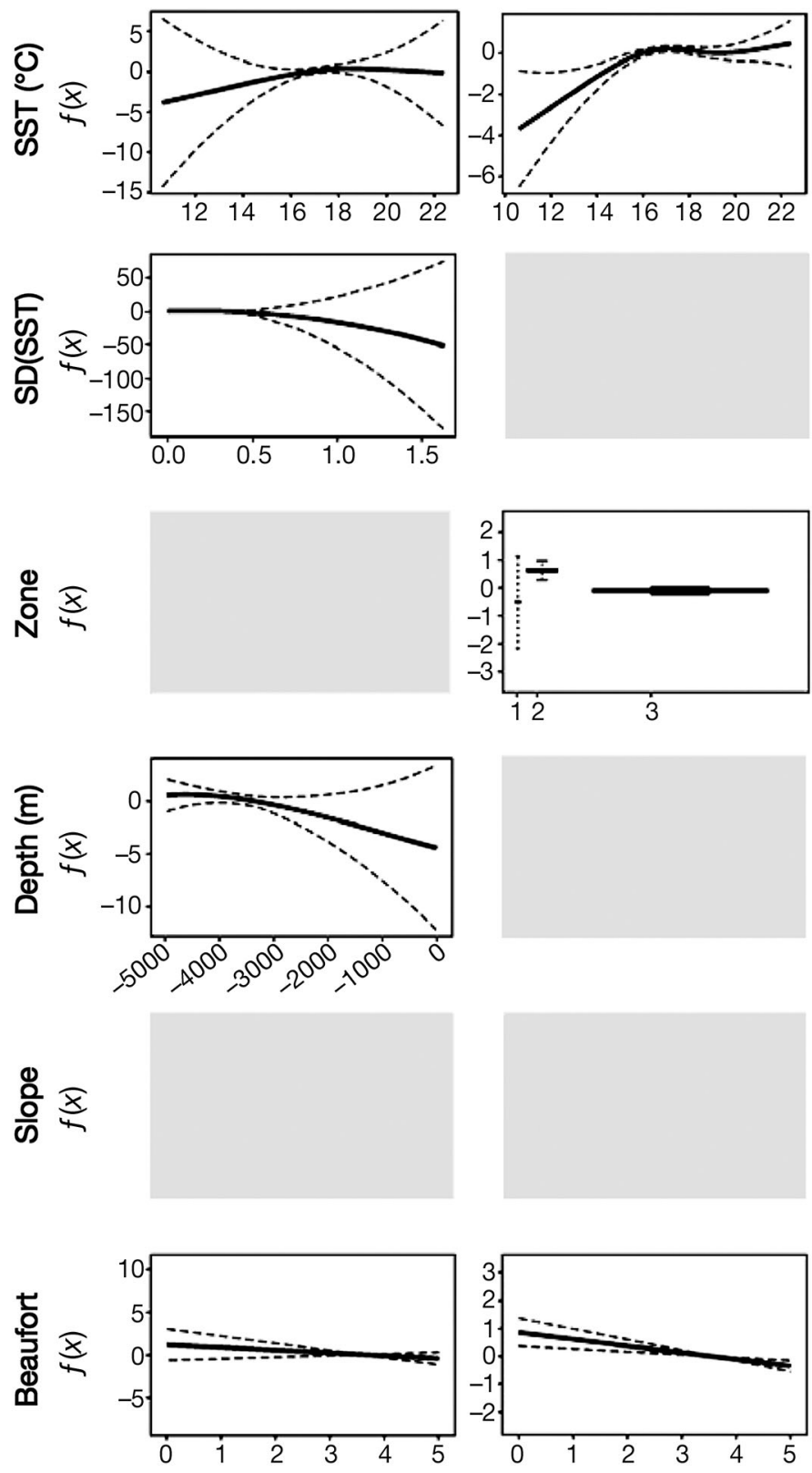
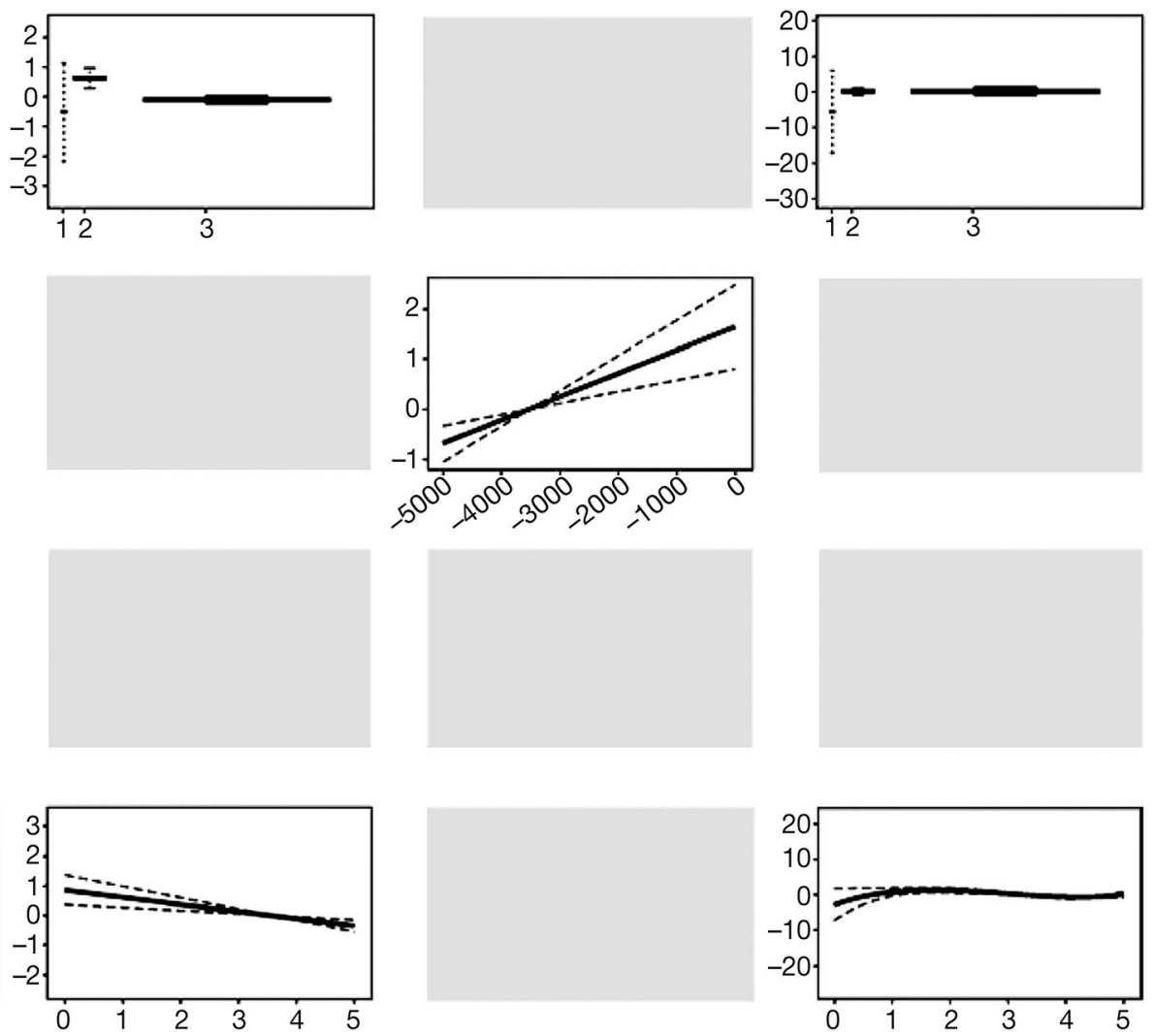

12
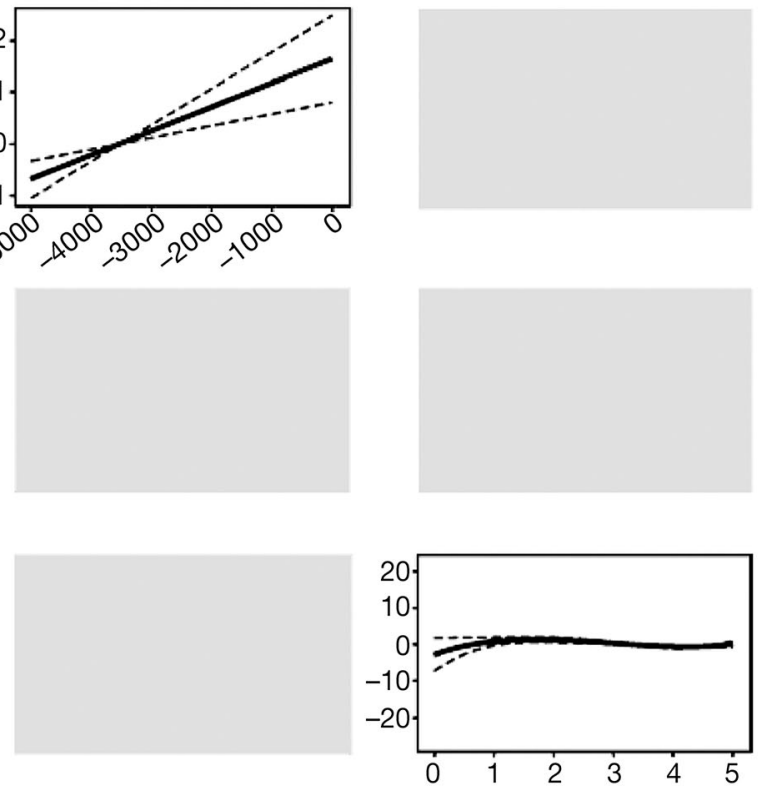

Risso's dolphin

Northern right whale dolphin
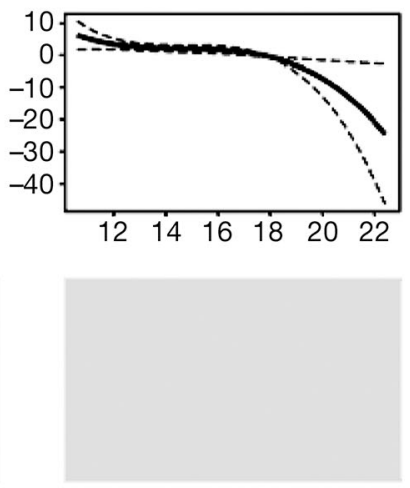

Fig. 2. Encounter rate model functions for: (a) striped dolphin, short-beaked common dolphin, Risso's dolphin, and northern right whale dolphin and (b) Dall's porpoise, fin whale, blue whale, and humpback whale. Shown are results from models built with remotely sensed data; for these species, models built with in situ data included the same key variables with similar functional forms. Models were constructed with both linear terms and either smoothing splines (GAMs) or polynomials (GLMs) having up to 3 degrees of freedom. Potential predictor variables included sea surface temperature (SST), the standard deviation (SD) of SST, oceanic zone (Zone), water depth (Depth), bathymetric slope (Slope), and Beaufort sea state (Beaufort). The $y$-axes represent the term's (linear, spline, or polynomial) function. Zero on the $y$-axes corresponds to no effect of the predictor variable on the estimated response variable (encounter rate). Functions have been scaled relative to the variable having the largest $y$-axis range that was not influenced by outliers. The dashed lines reflect $2 \times$ standard error bands (i.e. $95 \%$ confidence interval). Zone was modeled as a categorical variable defined roughly by water depth—1: shelf; 2 : slope; 3 : abyssal plain (see 'Methods—Habitat predictor variables' for more details). A grey box indicates the variable was not included in the model. Taxonomic names, see Table 1 

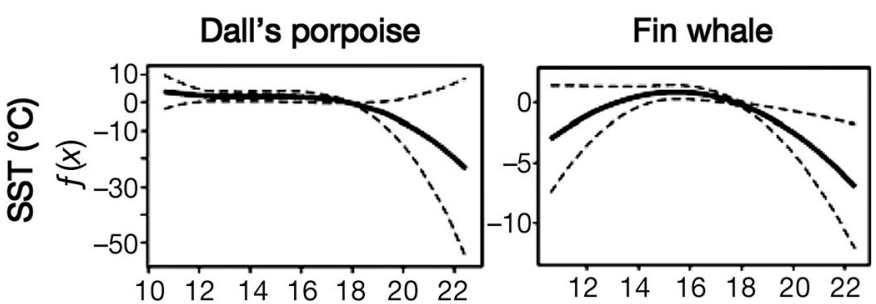

Blue whale
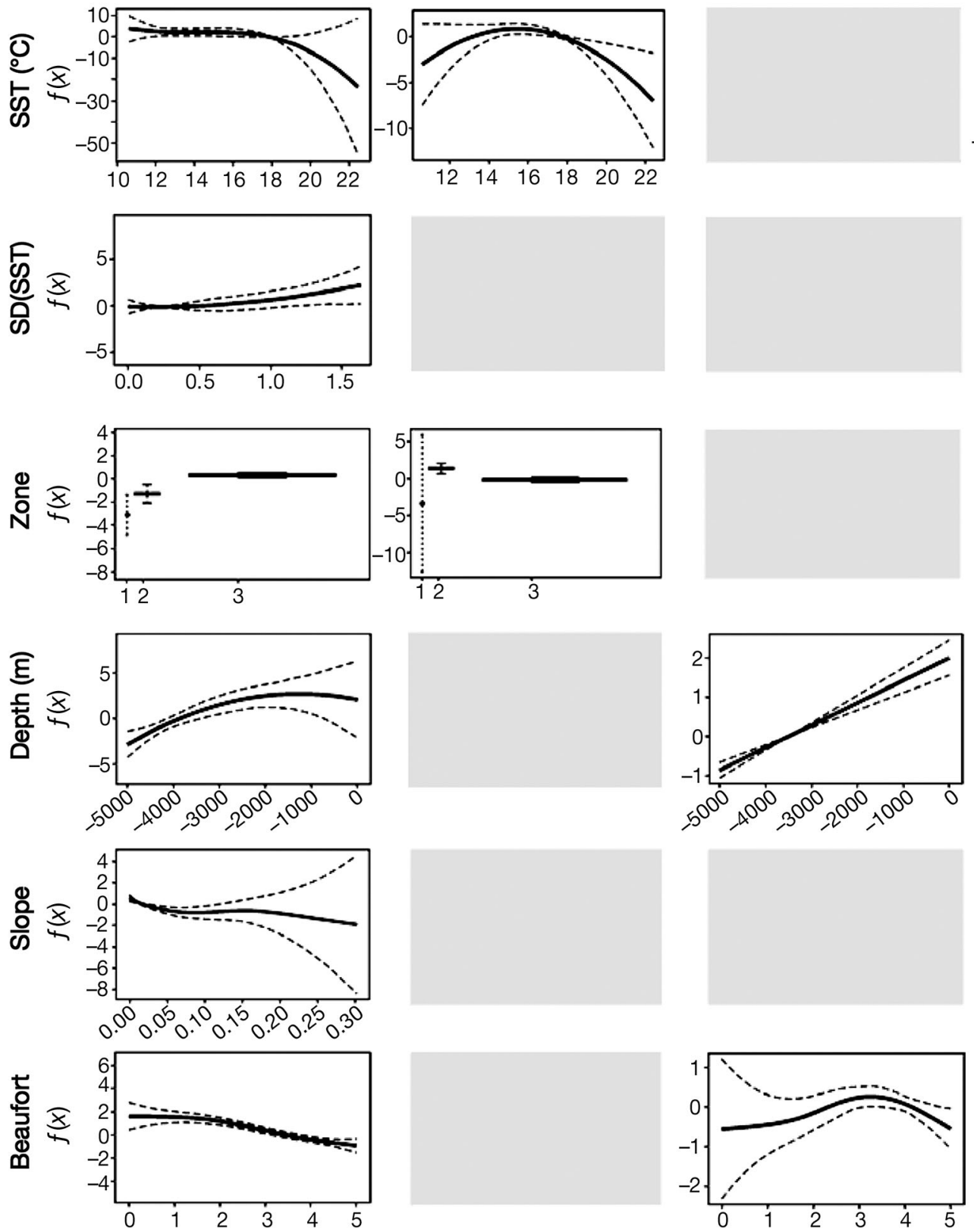
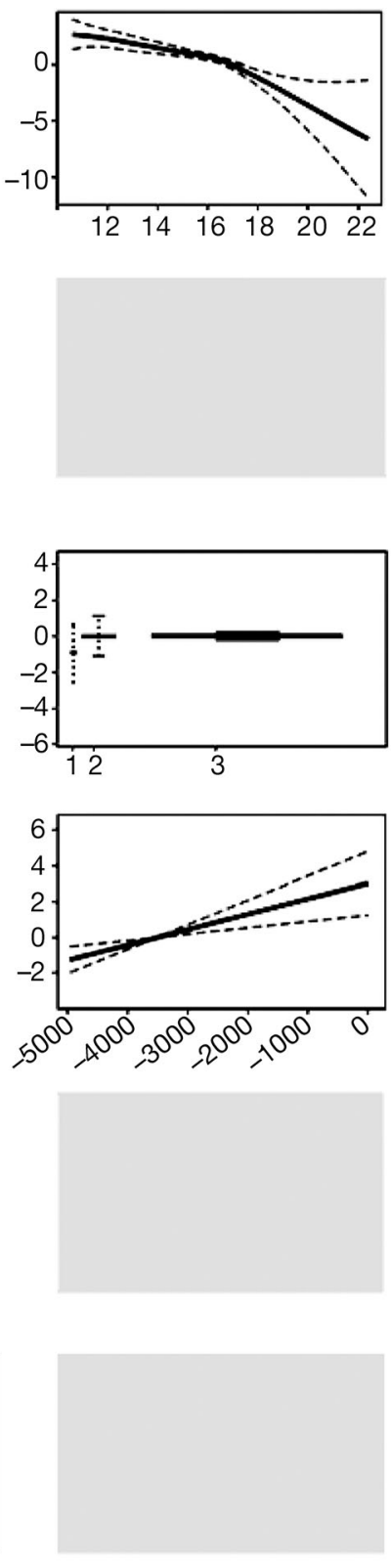

Fig. 2 (continued)

remotely sensed model predicted an almost linear increase in group size with increasing SST variation, suggesting that fin whales congregate at localized frontal regions. This result is consistent with that of Doniol-Valcroze et al. (2007), who found high correlations between the distribution of fin whales and thermal fronts in the Gulf of St. Lawrence. The model built with remotely sensed data had a lower ASPE value and a better predicted/standard density ratio than the model built with in situ data, suggesting that remotely sensed data may be more effective at characterizing frontal activity due to their ability to measure heterogeneity in 2 dimensions.

\section{Model performance}

For each of the 10 species considered in this analysis, we evaluated the performance of 2 models (encounter rate and group size) built with 2 types of SST data 

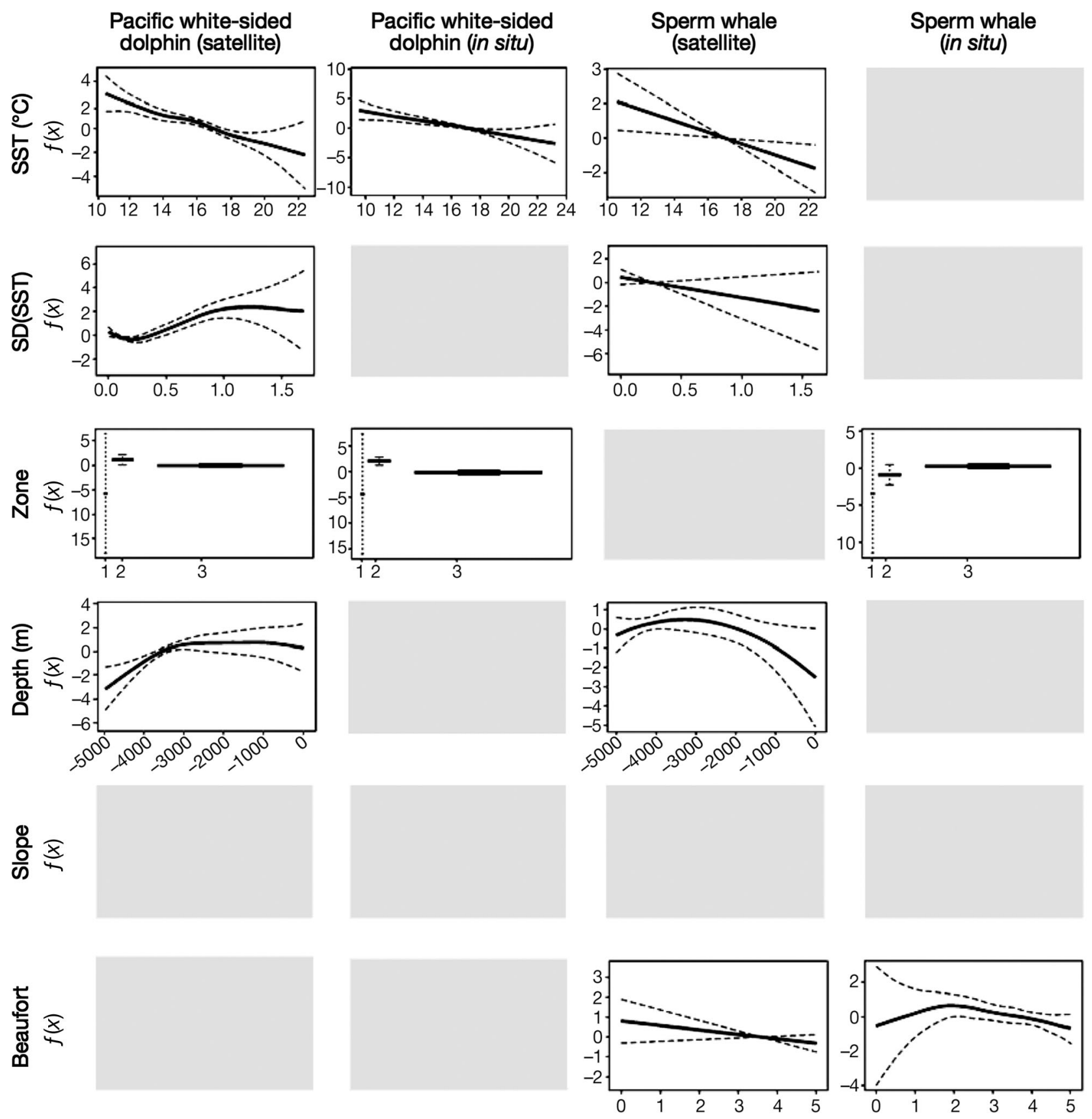

Fig. 3. Encounter rate model functions for Pacific white-sided dolphin and sperm whale. For these species, models built with remotely sensed data differed from those built with in situ data. Models were constructed with both linear terms and either smoothing splines (GAMs) or polynomials (GLMs) having up to 3 degrees of freedom. Potential predictor variables included sea surface temperature (SST), the standard deviation (SD) of SST, oceanic zone (Zone), water depth (Depth), bathymetric slope (Slope), and Beaufort sea state (Beaufort). The $y$-axes represent the term's (linear, spline, or polynomial) function. Zero on the $y$-axes corresponds to no effect of the predictor variable on the estimated response variable (encounter rate). Functions have been scaled relative to the variable having the largest $y$-axis range that was not influenced by outliers. The dashed lines reflect $2 \times$ standard error bands (i.e. $95 \%$ confidence interval). Zone was modeled as a categorical variable defined roughly by water depth-1: shelf; 2: slope; 3: abyssal plain (see 'Methods-Habitat predictor variables' for more details). A gray box indicates the variable was not included in the model. Taxonomic names, see Table 1 
Table 5. Proportion of deviance explained (Expl. Dev.) and average squared prediction error (ASPE) for the final encounter rate (ER) and group size (GS) models. Predictions are based on application of models to the data from which they were built, and thus provide an indication of explanatory power, i.e. model goodness-of-fit. The ER and GS model with the greatest explanatory power (as determined by lowest ASPE) for each species appears in bold. The number of samples and number of sightings reflect the numbers used to build the encounter rate models and depend on the satellite and in situ sea surface temperature data available for the species-specific spatial resolution. The large range of ASPE values for the group size models in part reflects the range of species-specific group sizes (e.g. short-beaked common dolphins tend to occur in highly variable groups of up to 1000s of animals, while blue whales are usually found singly or in small groups). Taxonomic names, see Table 1

\begin{tabular}{|c|c|c|c|c|c|c|c|}
\hline \multirow{2}{*}{ Species } & \multirow{2}{*}{$\begin{array}{l}\text { Number of } \\
\text { samples }\end{array}$} & \multirow{2}{*}{$\begin{array}{l}\text { Number of } \\
\text { sightings }\end{array}$} & \multirow{2}{*}{$\begin{array}{l}\text { Data } \\
\text { source }\end{array}$} & \multicolumn{2}{|c|}{$\longrightarrow$ ER models } & \multicolumn{2}{|c|}{ — GS models — } \\
\hline & & & & Expl. Dev. & ASPE & Expl. Dev. & ASPE \\
\hline Striped dolphin & 5755 & 49 & $\begin{array}{l}\text { Satellite } \\
\text { In situ }\end{array}$ & $\begin{array}{l}0.111 \\
0.058\end{array}$ & $\begin{array}{l}\mathbf{0 . 0 2 9} \\
0.034\end{array}$ & $\begin{array}{l}0.100 \\
0.108\end{array}$ & $\begin{array}{l}4100 \\
\mathbf{3 7 0 0}\end{array}$ \\
\hline Short-beaked common dolphin & 5928 & 306 & $\begin{array}{l}\text { Satellite } \\
\text { In situ }\end{array}$ & $\begin{array}{l}0.046 \\
0.049\end{array}$ & $\begin{array}{l}0.185 \\
\mathbf{0 . 1 8 3}\end{array}$ & $\begin{array}{l}0.070 \\
0.051\end{array}$ & $\begin{array}{l}\mathbf{5 2 2 0 0} \\
52400\end{array}$ \\
\hline Risso's dolphin & 6054 & 70 & $\begin{array}{l}\text { Satellite } \\
\text { In situ }\end{array}$ & $\begin{array}{l}0.053 \\
0.053\end{array}$ & $\begin{array}{l}0.056 \\
0.056\end{array}$ & $\begin{array}{l}0.071 \\
0.050\end{array}$ & $\begin{array}{l}\mathbf{5 3 1} \\
584\end{array}$ \\
\hline Pacific white-sided dolphin & 5500 & 25 & $\begin{array}{l}\text { Satellite } \\
\text { In situ }\end{array}$ & $\begin{array}{l}0.321 \\
0.227\end{array}$ & $\begin{array}{l}0.117 \\
\mathbf{0 . 0 6 0}\end{array}$ & $\begin{array}{l}0.544 \\
0.515\end{array}$ & $\begin{array}{l}4132 \\
\mathbf{1 8 1 4}\end{array}$ \\
\hline Northern right whale dolphin & 5928 & 40 & $\begin{array}{l}\text { Satellite } \\
\text { In situ }\end{array}$ & $\begin{array}{l}0.182 \\
0.174\end{array}$ & $\begin{array}{l}\mathbf{0 . 0 6 0} \\
0.075\end{array}$ & $\begin{array}{l}0.136 \\
0.046\end{array}$ & $\begin{array}{l}685 \\
712\end{array}$ \\
\hline Dall's porpoise & 5928 & 179 & $\begin{array}{l}\text { Satellite } \\
\text { In situ }\end{array}$ & $\begin{array}{l}0.393 \\
0.345\end{array}$ & $\begin{array}{l}\mathbf{0 . 0 3 0} \\
0.185\end{array}$ & $\begin{array}{l}0.031 \\
0.054\end{array}$ & $\begin{array}{l}9.32 \\
\mathbf{8 . 8 6}\end{array}$ \\
\hline Sperm whale & 6054 & 37 & $\begin{array}{l}\text { Satellite } \\
\text { In situ }\end{array}$ & $\begin{array}{l}0.052 \\
0.031\end{array}$ & $\begin{array}{l}0.070 \\
\mathbf{0 . 0 6 9}\end{array}$ & $\begin{array}{l}0.108 \\
0.250\end{array}$ & $\begin{array}{l}59.6 \\
\mathbf{5 3 . 3}\end{array}$ \\
\hline Fin whale & 5500 & 120 & $\begin{array}{l}\text { Satellite } \\
\text { In situ }\end{array}$ & $\begin{array}{l}0.101 \\
0.095\end{array}$ & $\begin{array}{l}\mathbf{0 . 0 5 4} \\
0.064\end{array}$ & $\begin{array}{l}0.069 \\
0.040\end{array}$ & $\begin{array}{l}2.15 \\
2.17\end{array}$ \\
\hline Blue whale & 6054 & 161 & $\begin{array}{l}\text { Satellite } \\
\text { In situ }\end{array}$ & $\begin{array}{l}0.111 \\
0.114\end{array}$ & $\begin{array}{l}\mathbf{0 . 1 3 1} \\
0.136\end{array}$ & $\begin{array}{l}0.079 \\
0.081\end{array}$ & $\begin{array}{l}0.747 \\
\mathbf{0 . 6 7 8}\end{array}$ \\
\hline Humpback whale & 6054 & 84 & $\begin{array}{l}\text { Satellite } \\
\text { In situ }\end{array}$ & $\begin{array}{l}0.342 \\
0.344\end{array}$ & $\begin{array}{l}\mathbf{0 . 0 9 3} \\
0.099\end{array}$ & $\begin{array}{l}0.097 \\
0.131\end{array}$ & $\begin{array}{l}2.975 \\
\mathbf{2 . 9 1 5}\end{array}$ \\
\hline
\end{tabular}

Table 6. Summary of the weighted average effective strip width [ESW $=1 / f(0)]$ and $g(0)$ estimates used to calculate standard and predicted densities for this analysis. The original values are those estimated from all the survey data (Barlow 2003), which accounted for both perception and availability bias to the extent possible. These values are weighted by the number of small and large groups observed during the 1991, 1993, 1996, and 2001 surveys for the segments included in each species-specific spatial resolution. Taxonomic names, see Table 1

\begin{tabular}{|c|c|c|c|c|c|}
\hline \multirow{2}{*}{ Species } & \multirow{2}{*}{ Group size } & \multicolumn{2}{|c|}{$\mathrm{ESW}$} & \multirow[b]{2}{*}{ Original } & \multirow[b]{2}{*}{$\begin{array}{l}\text { Weighted } \\
\text { average }\end{array}$} \\
\hline & & Original & $\begin{array}{l}\text { Weighted } \\
\text { average }\end{array}$ & & \\
\hline Striped dolphin & $\begin{array}{c}1-20 \\
21-100 \\
100+\end{array}$ & $\begin{array}{l}0.50 \\
1.24 \\
1.88\end{array}$ & 0.927 & $\begin{array}{l}0.77 \\
1.00 \\
1.00\end{array}$ & 0.883 \\
\hline Short-beaked common dolphin & $\begin{array}{c}1-20 \\
21-100 \\
100+\end{array}$ & $\begin{array}{l}0.50 \\
1.24 \\
1.88\end{array}$ & 1.331 & $\begin{array}{l}0.77 \\
1.00 \\
1.00\end{array}$ & 0.950 \\
\hline Risso's dolphin & $\begin{array}{c}1-20 \\
20+\end{array}$ & $\begin{array}{l}1.37 \\
2.18\end{array}$ & 1.615 & $\begin{array}{l}0.74 \\
1.00\end{array}$ & 0.819 \\
\hline Pacific white-sided dolphin & $\begin{array}{c}1-20 \\
21-100 \\
100+\end{array}$ & $\begin{array}{l}0.50 \\
1.24 \\
1.88\end{array}$ & 0.847 & $\begin{array}{l}0.77 \\
1.00 \\
1.00\end{array}$ & 0.862 \\
\hline Northern right whale dolphin & $\begin{array}{c}1-20 \\
21-100 \\
100+\end{array}$ & $\begin{array}{l}0.50 \\
1.24 \\
1.88\end{array}$ & 0.782 & $\begin{array}{l}0.77 \\
1.00 \\
1.00\end{array}$ & 0.853 \\
\hline Dall's porpoise ${ }^{a}$ & All & 0.82 & 0.82 & 0.79 & 0.79 \\
\hline Sperm whale & All & 4.61 & 4.61 & 0.87 & 0.87 \\
\hline Fin whale & All & 1.72 & 1.72 & 0.90 & 0.90 \\
\hline Blue whale & All & 1.72 & 1.72 & 0.90 & 0.90 \\
\hline Humpback whale & All & 2.89 & 2.89 & 0.90 & 0.90 \\
\hline
\end{tabular}


Table 7. Standard line-transect (standard) and model-predicted density estimates (animals $\mathrm{km}^{-2}$ ) and the associated standard errors (SE; shown in parentheses) based on results from the final remotely sensed (satellite) and in situ models. Predicted densities are based on application of the encounter rate and group size models to all segments of the datasets prior to interpolation. Ratios: model predicted/standard density estimates. The model with the ratio closest to 1.000 appears in bold, to illustrate the model that is most similar to standard line-transect results. Taxonomic names, see Table 1

\begin{tabular}{|c|c|c|c|c|c|c|}
\hline \multirow[t]{2}{*}{ Species } & \multirow{2}{*}{$\begin{array}{l}\text { Number of } \\
\text { sightings }\end{array}$} & \multicolumn{3}{|c|}{ - Density estimates - } & \multicolumn{2}{|c|}{$\longrightarrow$ Ratios -} \\
\hline & & Standard (SE) & Satellite (SE) & In situ (SE) & Satellite & In situ \\
\hline Striped dolphin & 49 & $0.0499(0.0160)$ & $0.0501(0.0067)$ & $0.0496(0.0043)$ & 1.004 & 0.994 \\
\hline Short-beaked common dolphin & 306 & $0.6726(0.1214)$ & $0.6713(0.0572)$ & $0.6733(0.0335)$ & 0.998 & 1.001 \\
\hline Risso's dolphin & 70 & $0.0172(0.0034)$ & $0.0231(0.0010)$ & $0.0219(0.0007)$ & 1.343 & 1.273 \\
\hline Pacific white-sided dolphin & 25 & $0.0350(0.0152)$ & $0.0325(0.0097)$ & $0.0226(0.0022)$ & 0.929 & 0.646 \\
\hline Northern right whale dolphin & 40 & $0.0246(0.0065)$ & $0.0248(0.0028)$ & $0.0248(0.0029)$ & 1.009 & $1.008^{\mathrm{a}}$ \\
\hline Dall's porpoise & 179 & $0.0449(0.0038)$ & $0.0441(0.0019)$ & $0.0460(0.0022)$ & 0.982 & 1.024 \\
\hline Sperm whale & 37 & $0.0012(0.0005)$ & $0.0011(0.0001)$ & $0.0010(0.0001)$ & 0.917 & 0.833 \\
\hline Fin whale & 120 & $0.0028(0.0005)$ & $0.0028(0.0002)$ & $0.0028(0.0002)$ & $1.009^{\mathrm{a}}$ & 1.018 \\
\hline Blue whale & 161 & $0.0030(0.0008)$ & $0.0031(0.0001)$ & $0.0031(0.0001)$ & $1.017^{\mathrm{a}}$ & 1.021 \\
\hline Humpback whale & 84 & $0.0018(0.0003)$ & $0.0019(0.0002)$ & $0.0019(0.0001)$ & $1.038^{\mathrm{a}}$ & 1.050 \\
\hline
\end{tabular}

a) Striped dolphin

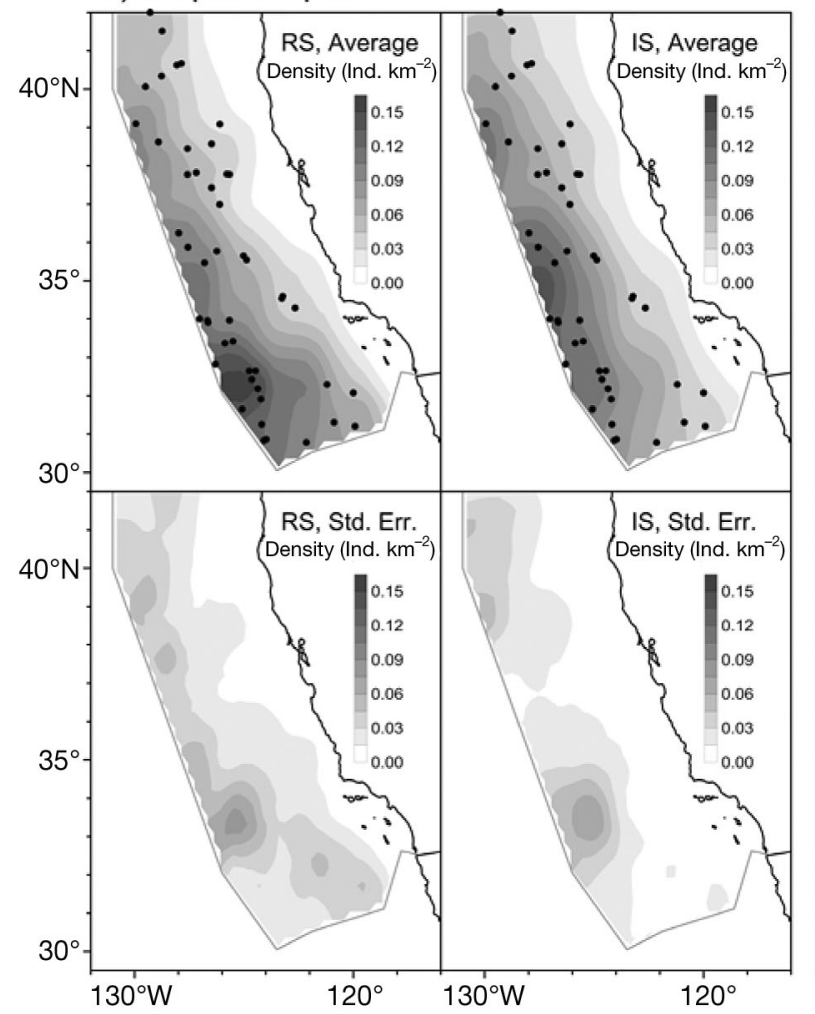

b) Short-beaked common dolphin

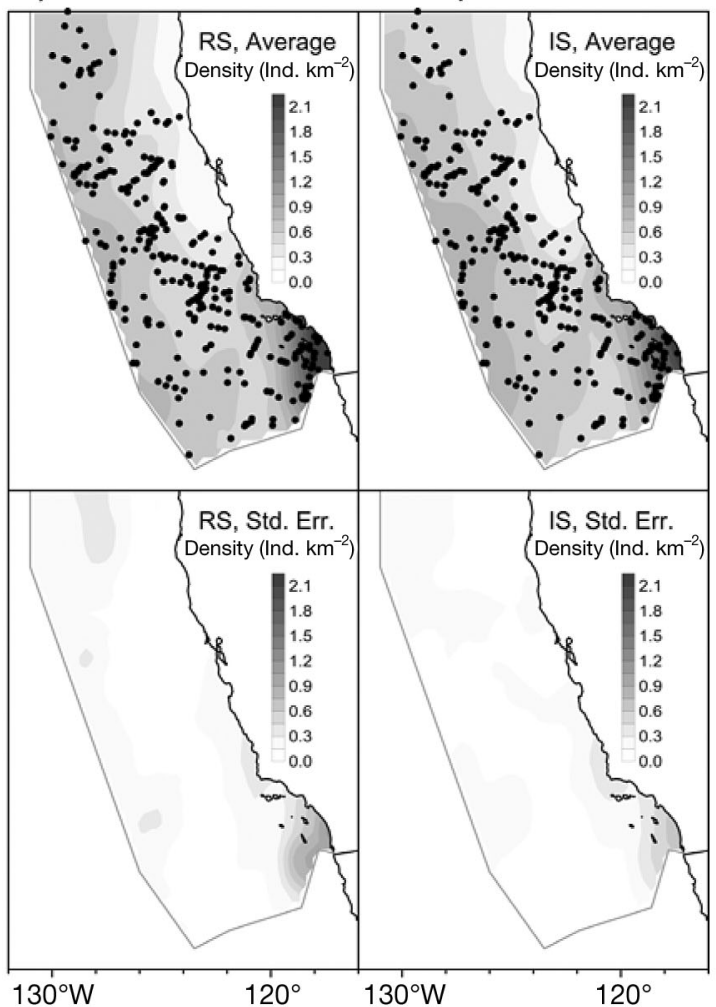

Fig. 4. Predicted relative density estimates and standard errors from the models built with remotely sensed (RS) and in situ (IS) data for: (a) striped dolphin, (b) short-beaked common dolphin, (c) Risso's dolphin, (d) Pacific white-sided dolphin, (e) northern right whale dolphin, (f) Dall's porpoise, (g) sperm whale, (h) fin whale, (i) blue whale, and (j) humpback whale. Predictions are shown for the study area. Interpolation grids were created at a resolution of $25 \mathrm{~km}$, using inverse distance weighting to the second power in Surfer software (Vers 8). The same species-specific relative density scale was used to enable comparisons between model types (remotely sensed and in situ). Models with obvious outliers were scaled so that differences in predicted densities at lower levels were visible. White is used to indicate the lowest density ranges; there were almost no 'zero' predictions. Black dots show sighting locations. Taxonomic names, see Table 1 
c) Risso's dolphin

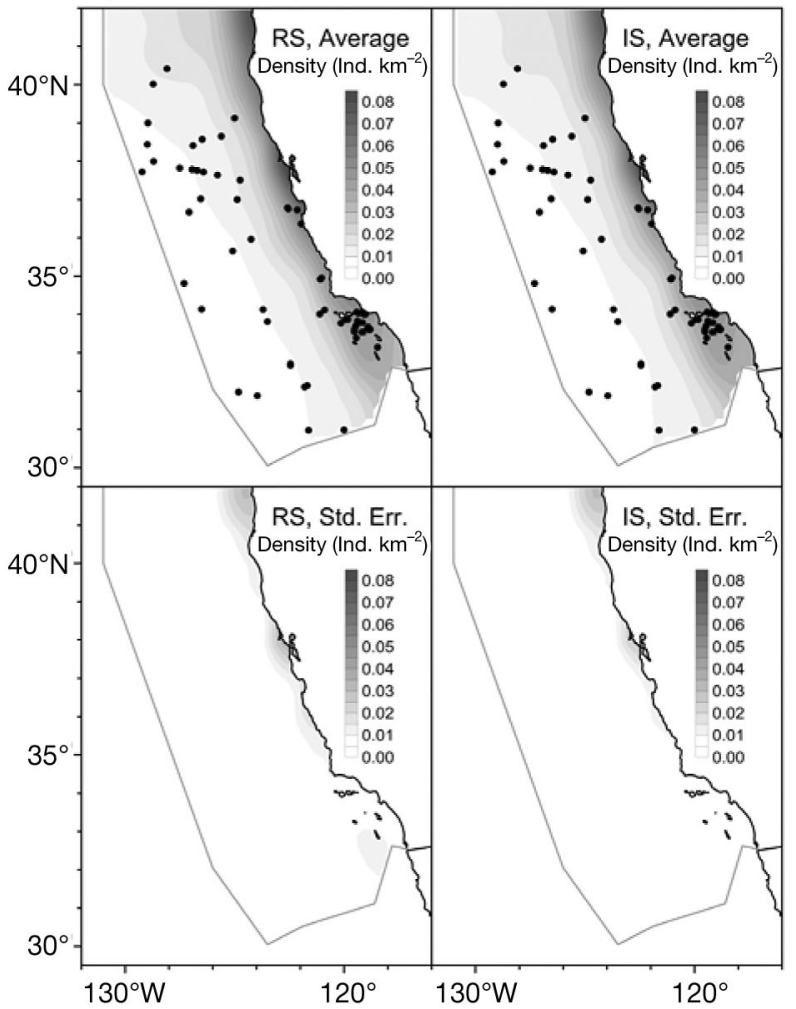

e) Northern right whale dolphin

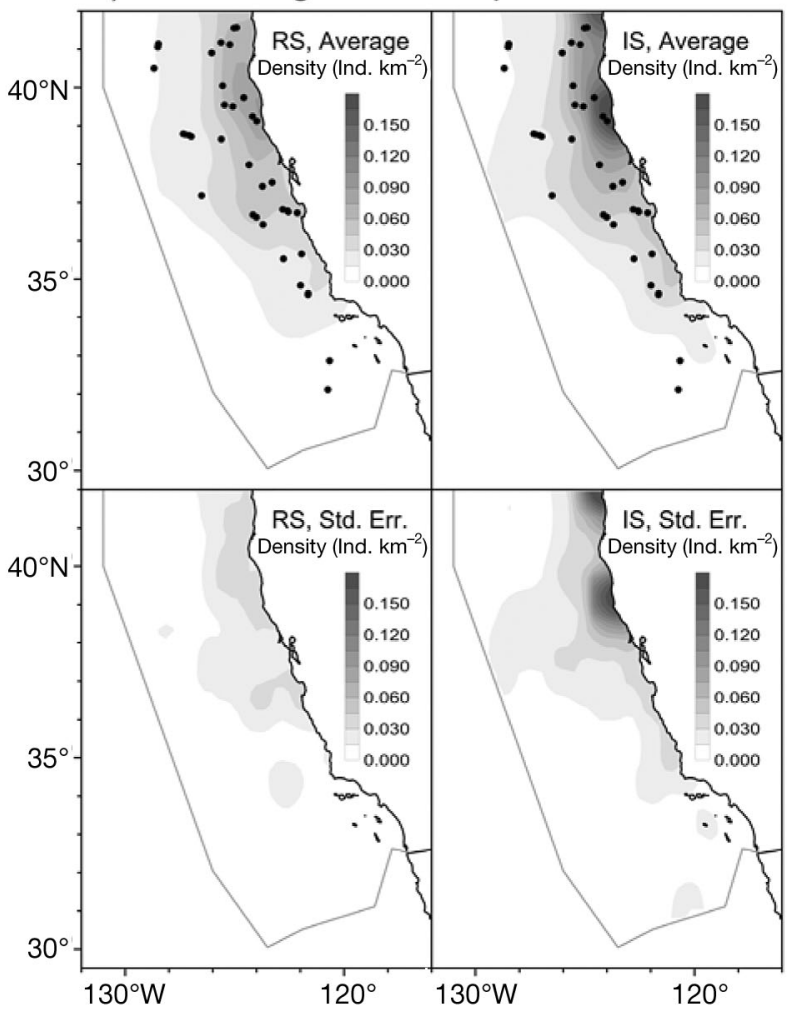

d) Pacific white-sided dolphin

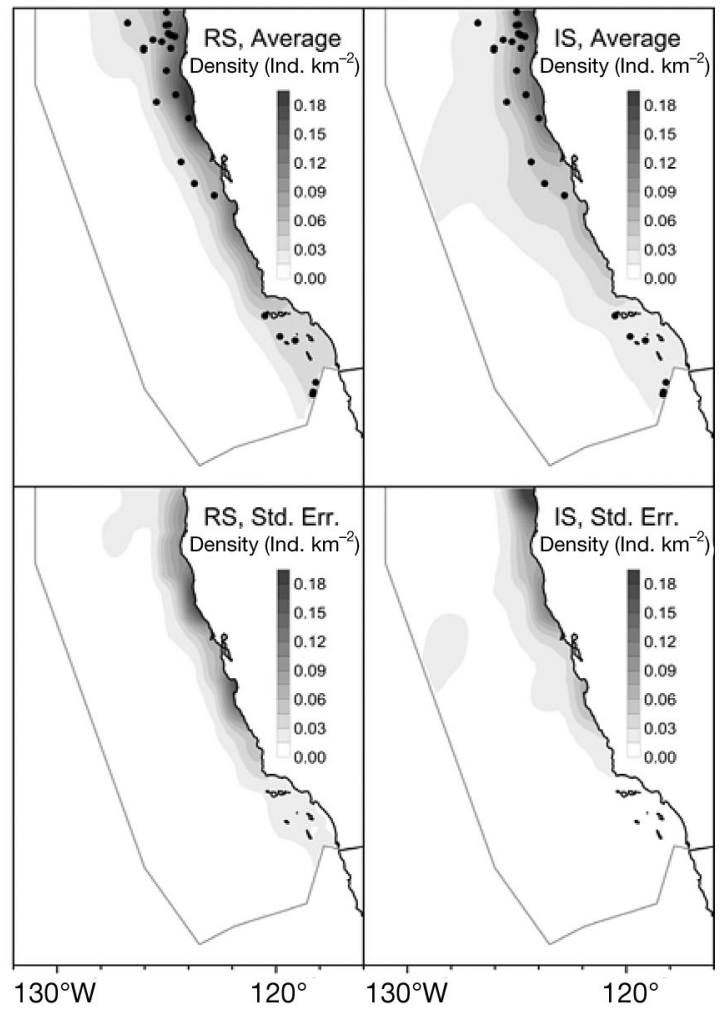

f) Dall's porpoise

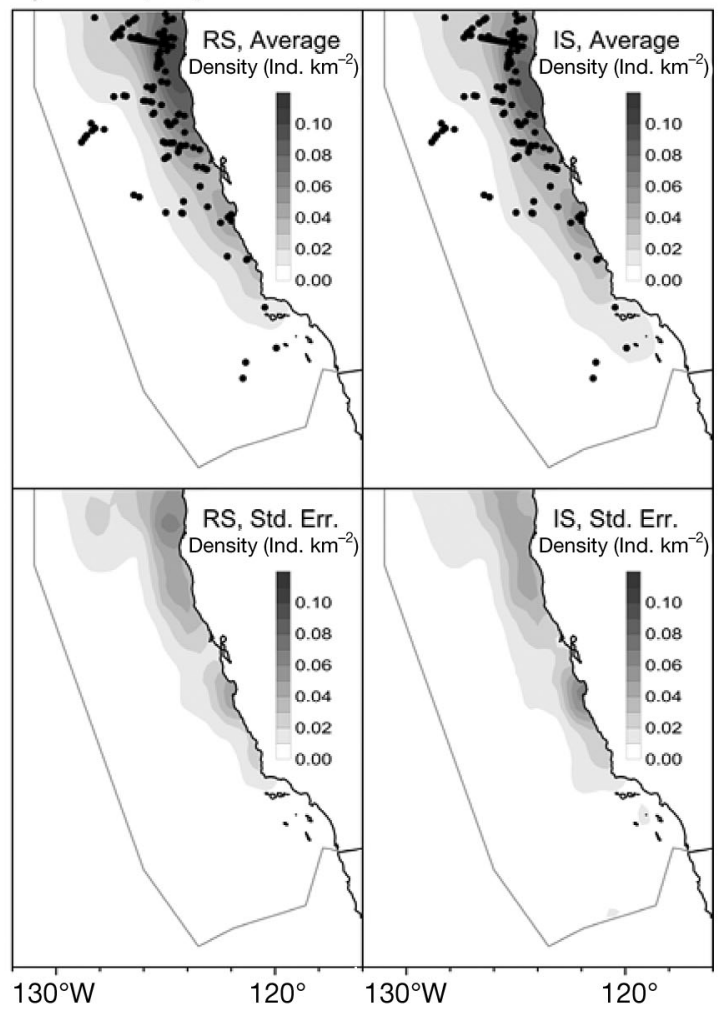

Fig. 4 (continued) 
g) Sperm whale

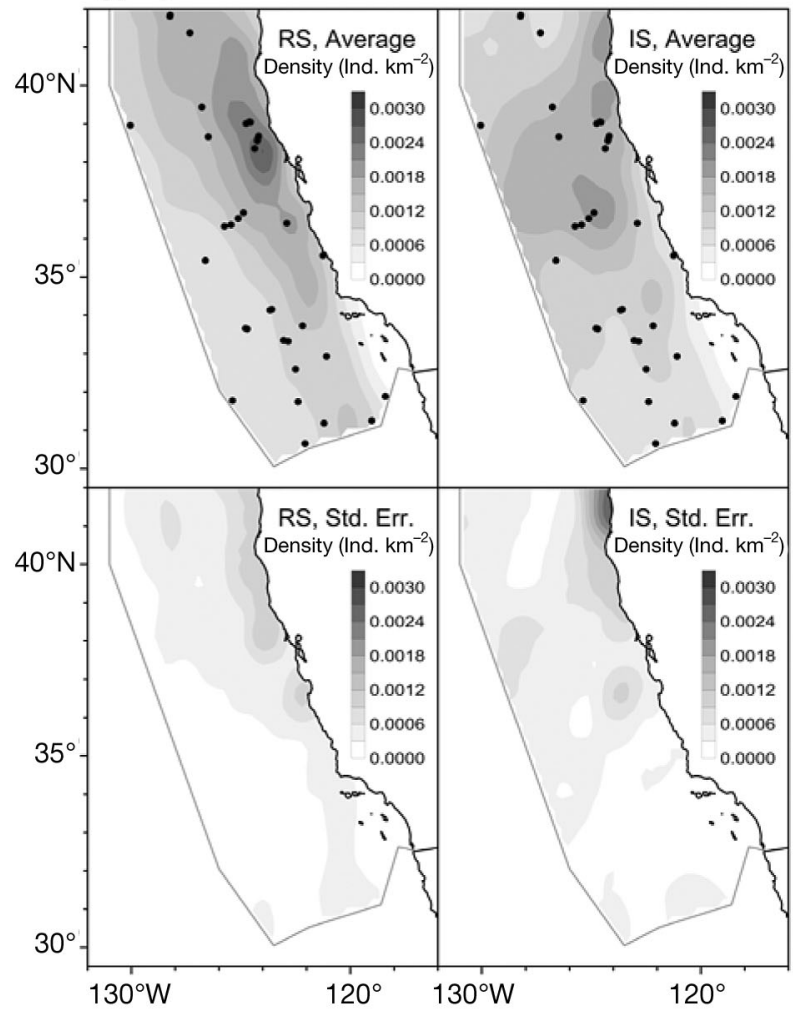

i) Blue whale

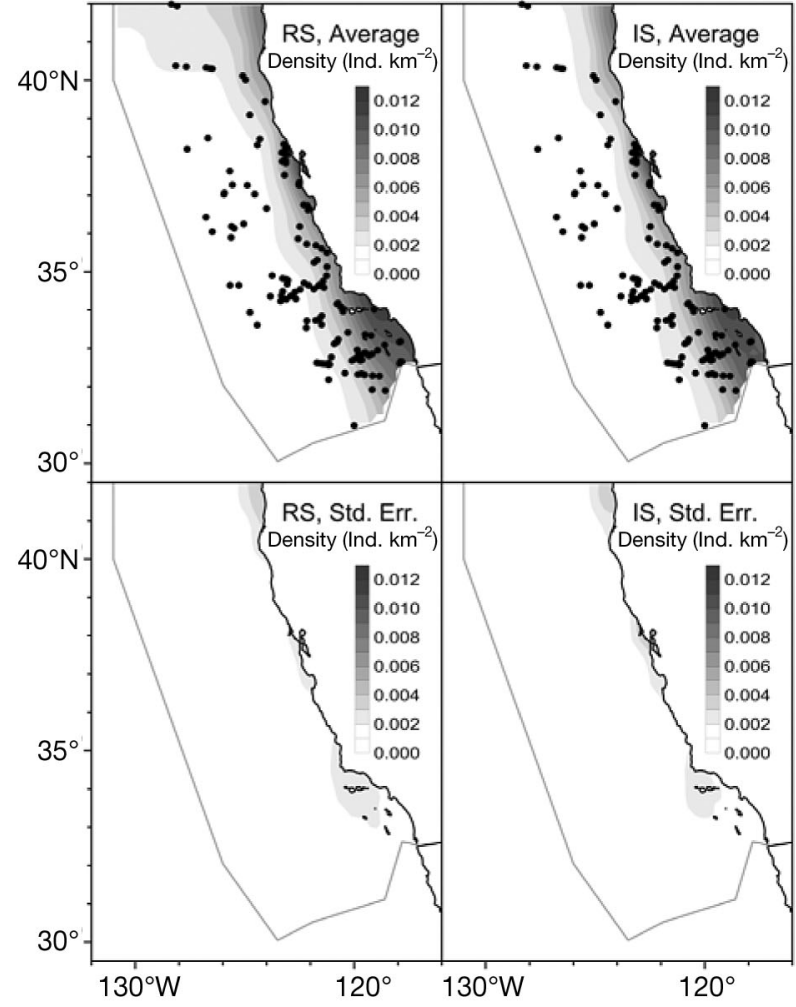

h) Fin whale

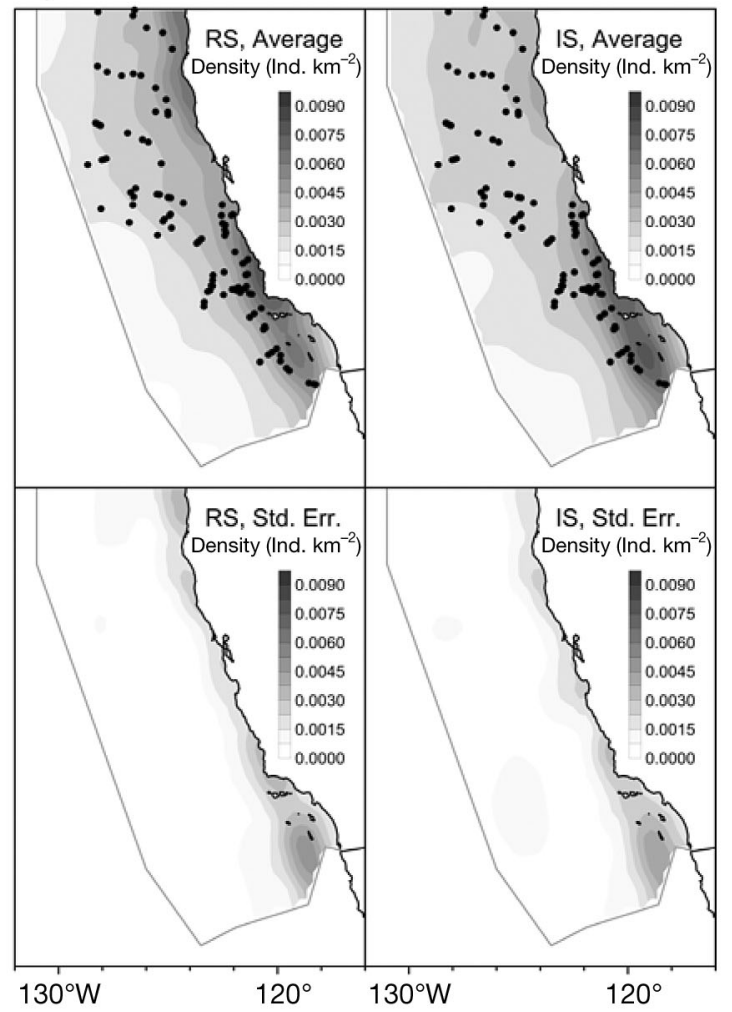

j) Humpback whale

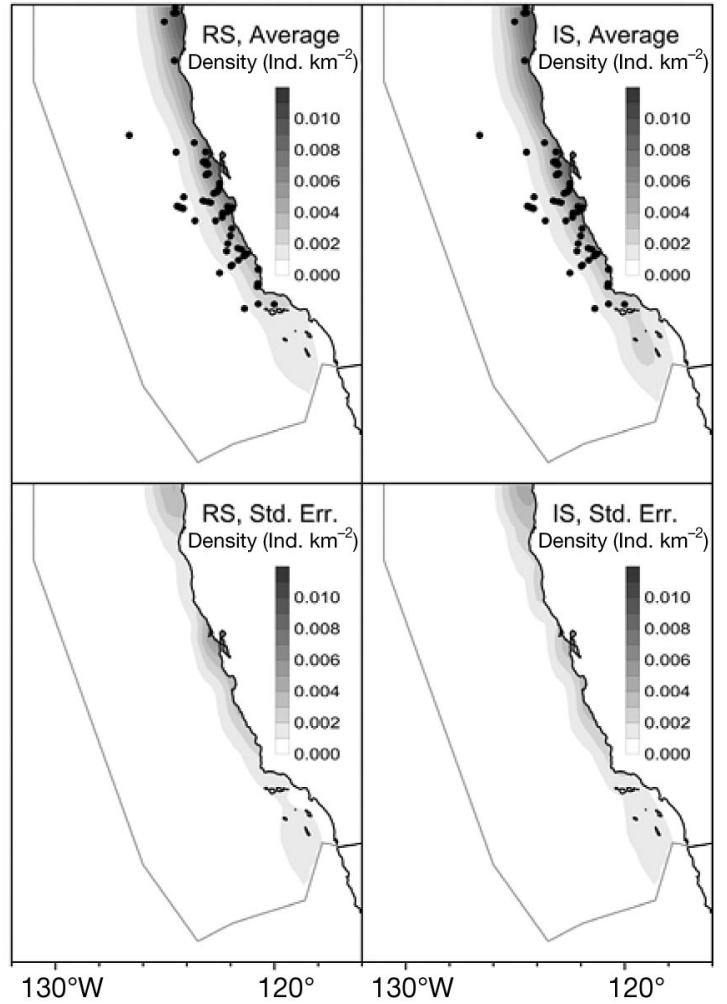

Fig. 4 (continued) 
(remotely sensed and in situ), for a total of 4 models per species.

Models built with remotely sensed and in situ measures of SST and its variance exhibited similar explanatory performance as evident from a comparison of explained deviance and ASPE (Table 5). Overall, encounter rate models built with remotely sensed data tended to have lower ASPE values on a speciesby-species basis, while models built with in situ data tended to have lower ASPE values for the group size models. There were some differences for some species, but explanatory power was not consistently higher for models built with one of the data sources.

In general, we saw relatively good agreement between the standard density estimates and predicted values (Table 7). Density predictions for striped dolphin, short-beaked common dolphin, northern right whale dolphin, Dall's porpoise, fin whale, blue whale, and humpback whale were very close to standard densities estimated directly from the sighting data (the ratio of predicted/standard values ranged from 0.982 to 1.050). Performance was similar for models built with remotely sensed versus in situ data (Table 7 and Fig. 4). For most of these species, at least 80 sightings were used to build the models. The models built for Pacific white-sided dolphin $(\mathrm{n}=25)$ exhibited the poorest predictive performance; predicted density estimates generated by the in situ model differed by $>35 \%$ from the standard density estimates. In sum, models with predicted/standard density ratios furthest from 1:1 generally were associated with those species with the fewest sightings available for model development. Although line-transect estimates are not necessarily unbiased, this finding suggests that a minimum number of sightings is required to produce unbiased models for each species.

In addition to sample size, the predictive ability of cetacean-environment models is affected by the level of complexity of the species' habitat. More data were required to parameterize models for species that inhabit diverse environments. For example, despite small sample size $(n=49)$, all the models for striped dolphin had ratios of predicted to standard density estimates that approached one (Table 7). Striped dolphins are found in tropical and warm-temperate offshore waters (Perrin et al. 1994), and the key predictor variables included in the models, depth and SST, captured this pattern adequately with few data. In contrast, Pacific white-sided dolphins occur primarily in shelf and continental slope waters off California that are oceanographically more complex (e.g. highly variable bathymetry, water temperature, etc.), and more data were required for model parameterization.

Data loss due to cloud cover is one of the main disadvantages associated with using satellite data from passive infrared sensors such as the advanced very high resolution radiometer (AVHRR). In the California study area, persistent cloud cover is often associated with coastal upwelling areas in summer, indicating that models built with remotely sensed data are somewhat habitat dependent. Satellite-derived SST data were available for only $67 \%$ of the database segments that included sightings of Dall's porpoise (Table 2), a species known to be associated with coastal, upwelled water (Forney 2000, present study). In contrast, these data were available for $78 \%$ of the segments containing sightings of the short-beaked common dolphin, a species associated with warmer, offshore water (Forney 2000, present study).

The potential reduction in sample size available for model building can be partially overcome by averaging SST data over larger spatial resolutions, which for many species yielded greater predictive ability than smaller spatial scales. SST data obtained from microwave radiometers could help prevent data loss due to cloud cover and should be evaluated in future studies. Satellite data may never provide precise measures of water-column properties or prey indices currently available from in situ data; however, their repetitive and 2 dimensional coverage of broad ocean areas on a near real-time basis can enable timely predictions to support resource management decisions. In addition, satellite data allow for spatial predictions to be made over an entire study area, since, unlike in situ data that are limited by the areas surveyed, covariate data are generally available for all grid cells (except where cloud cover is a problem). The ability to predict densities for entire study areas could significantly improve our identification and interpretation of interannual changes in cetacean distribution. Future improvements to cetacean density models may be possible using new satellite-derived products and environmental data derived from dynamic physical oceanographic models. Such variables may lead to advances in near real-time predictive modeling and provide further insight into the ecological relationships between cetaceans and their environment.

\section{Distribution patterns}

Evaluation of the final models revealed that the functional forms of key variables were generally consistent with known distribution patterns for all of the species except Risso's dolphin. Visual inspection of the predicted species densities plots and actual sighting locations confirm that models for 8 of the 10 species (striped dolphin, short-beaked common dolphin, Pacific white-sided dolphin, northern right whale dolphin, Dall's porpoise, sperm whale, fin whale, and hump- 
back whale) were able to capture spatial distribution patterns in the study area (Fig. 4). The ability of the models to identify previously described species- environment relationships is briefly summarized for each species below.

As noted above, striped dolphins are found in warm waters offshore, and the key predictor variables included in the models, depth and SST, effectively predicted greater numbers of encounters and animals in relatively warm, deep waters.

Encounters with short-beaked common dolphin were most common in waters with temperatures $\geq 16^{\circ} \mathrm{C}$, consistent with the warm-temperate/tropical distribution range for this species (Evans 1994). Previous studies have suggested that Delphinus spp. concentrate along areas of high relief within the Southern California Bight (Hui 1979). Slope was not included in any of our final models. Differences between our results and those of Hui (1979) could be attributed to the additional variables included in our analysis (i.e. temperature and zone), which appear to have more of an effect on abundance of short-beaked common dolphins than does slope. In addition, there were differences in how slope was measured in the 2 studies; Hui used a categorical index with 5 categories of contour intervals, whereas we used a continuous variable. The greatest difference, however, was the extent of the study areas; our study area was broad, whereas Hui analyzed data from a localized area in the Southern California Bight.

Each model for Risso's dolphin contained only 1 linear predictor (Table 4), suggesting that the environmental variables used in the present study were not effective at capturing the distribution patterns for this species. Poor model performance is clearly evident in the smoothed density plots for this species. The predicted densities show little correlation with the actual sightings, on which the models were based (Fig. 4c). Poor model performance may be attributed in part to the relatively small sample size $(n=70)$, or it may indicate more complex ecological relationships that were not adequately captured with our set of predictor variables.

Key variables included in the encounter rate models for Pacific white-sided dolphin were SST and either depth or zone, with more encounters predicted for cooler waters over the continental slope, consistent with known distribution patterns (Barlow \& Forney 2007). SD(SST) was also included in the remotely sensed encounter rate model and both group size models for Pacific white-sided dolphin, showing more frequent encounters and larger groups in regions with greater SST variation (frontal regions). The in situ model for Pacific white-sided dolphin exhibited poor performance, as indicated by the predicted/standard density ratio $(0.646$; Table 7$)$, particularly when compared to the same ratio for the remotely sensed model (0.929). The smoothed density plots for these models were also very different, with the remotely sensed model appearing to capture the general distribution of Pacific white-sided dolphin in the study area, while the in situ model predicted higher densities extending well offshore in the central portion of the study area where there were no sightings of this species during any of the survey years (Fig. 4d). The enhanced performance of the remotely sensed model is likely due to the inclusion of the depth variable in the encounter rate model, which shows encounters dropping substantially in waters deeper than about $3000 \mathrm{~m}$.

The encounter rate models for northern right whale dolphins showed a 'threshold effect' for SST, indicating that encounters dropped substantially in water temperatures greater than about $16^{\circ} \mathrm{C}$ (Fig. 2a). This result is consistent with this species' tendency to occur in relatively colder waters off California (Leatherwood et al. 1982, Jefferson et al. 1994). Northern right whale dolphins feed primarily on mesopelagic fish and squid, and are known to occur frequently with other cetaceans, particularly Pacific white-sided dolphins (Jefferson et al. 1994). Interestingly, a less pronounced but similar threshold effect for SST was also included in the remotely sensed encounter rate model for Pacific white-sided dolphin (encounters decreasing rapidly at water temperatures greater than about $16^{\circ} \mathrm{C}_{i}$ Fig. 3).

Key predictor variables in the Dall's porpoise encounter rate models included SST, depth, and Beaufort sea state. These terms were similar in functional form to encounter rate GAMs developed for this species by Forney (2000), confirming its preference for cooler, upwelling-modified water.

All the final models for sperm whale included either the zone or depth variable. The functional form of the depth variable in the encounter rate model built with satellite data shows encounters increasing with increasing depth up to about $3500 \mathrm{~m}$, and then declining slightly (Fig. 3). In the in situ model, highest encounters are shown in waters deeper than $2000 \mathrm{~m}$ (i.e. in Zone 3; Fig. 3). This species' apparent preference for deep waters is consistent with past observations (Leatherwood et al. 1982). This distribution pattern also is consistent with survey data collected monthly in the study area north of Point Conception during the period from 1980 to 1983: the majority of the 67 sperm whale sightings were in slope waters or deeper (Dohl et al. 1983). Both the group size models for this species suggest that larger groups occur in deeper waters; however, this could be an artifact of the small number of sightings $(\mathrm{n}=2)$ in waters $<2000 \mathrm{~m}$ deep. Sperm whales occur in highly variable group sizes of 1 (often a solitary male) up to 50 or more 
(Leatherwood et al. 1982). Sample size permitting, future analyses should examine whether solitary individuals occupy different habitats than the larger groups of animals.

The key variables included in the encounter rate models for fin whales were identical, and their functional forms very similar. Both models included zone, indicating most encounters over the continental slope, and SST, with most encounters in moderate-temperature waters $\left(14\right.$ to $19^{\circ} \mathrm{C}$, maximal at about 16 to $17^{\circ} \mathrm{C}_{i}$ Fig. 2b). Aggregations of fin whale have been observed year-round in central/southern California, with an increase in numbers in summer and fall (Forney \& Barlow 1998). Based on the sighting data, both models accurately predicted regions with the highest fin whale densities (Fig. 4h); however, the remotely sensed model appears to be more effective at capturing overall study area distribution as indicated by the sighting locations from 1991 to 2001 . This could be due to the difference in $\mathrm{SD}(\mathrm{SST})$ measures discussed previously.

The 2 encounter rate models for blue whale differed only in their inclusion of the depth variable; the in situ model included the categorical zone variable, whereas the remotely sensed model included the continuous depth variable. The zone variable indicated highest encounter rates were on the shelf and slope, with encounter rate dropping significantly in waters deeper than $2000 \mathrm{~m}$, while depth was included as a linear term that showed decreasing encounters with increasing water depth (Fig. 2b). Both models are consistent with what is known about this species, as blue whales feed off California in shelf and slope waters during summer and fall (roughly June through November; Calambokidis et al. 2003), but can also be found in lower densities in offshore waters (Barlow \& Forney 2007).

Despite the overall good model performance indicated by the blue whale predicted/observed density estimates (1.017 to 1.021), smoothed density plots suggest that the models were not able to capture the spatial distribution patterns of blue whales in the study area (Fig. 4i). The density predictions derived for the entire study area do not provide information on how well the models captured spatial patterns. Areas with the highest predicted densities of blue whales were the shelf and slope regions along the entire coast. The failure of the models to predict areas of higher density further offshore where animals were sighted during the 1991 to 2001 surveys indicates that the environmental variables considered in the present study did not fully capture the distribution patterns for this species.

Predictor variables with the largest effect on humpback whale encounter rates included SST and depth. Sighting rates decreased in waters warmer than about $17^{\circ} \mathrm{C}$ and were higher in shallow than deep waters. These variables are consistent with the known distrib- ution patterns of humpback whales off California, where they congregate to feed during spring, summer, and fall (Calambokidis et al. 2001).

\section{CONCLUSIONS}

The main goals of the present study were to examine the most effective resolutions of satellite-derived SST for cetacean-habitat models, to compare the performance of models built with remotely sensed versus in situ data, and to compare cetacean densities derived from model predictions to those estimated using standard line-transect methods. For most species, predictive ability was greater at the coarser SST spatial resolutions included in our analysis. Although results varied by species, encounter rate and group size models built with remotely sensed or in situ SST data exhibited similar explanatory and predictive performance. Low sample size is problematic for both types of data; however, if sample size is sufficient (ideally $>80$ sightings), models built with remotely sensed measures of SST can perform as well, and in some cases better, than models built with in situ measures. It is likely that models built with remotely sensed data are more appropriate for some species than others, particularly those species that exhibit a strong association to SST (e.g. Dall's porpoise) or SST fronts (e.g. Pacific white-sided dolphins). However, additional years of data and tests on novel datasets are needed to resolve species-specific model performance. We found that the density values derived from predictive models built with both remotely sensed and in situ data captured spatial patterns for most species and were similar to those estimated using standard line-transect methods. This finding suggests that habitat modeling using remotely sensed environmental variables may provide an alternative method for estimating cetacean densities in near real-time over broad scales and varying resolutions.

Acknowledgements. We are very thankful to everyone who spent long hours collecting the data used in our analyses, including the marine mammal observers, oceanographers, cruise leaders, officers, and crew of the RV 'David Starr Jordan' and RV 'McArthur'. S. Reilly and L. Ballance served as Ecosystem Program Leaders during the shipboard surveys. We thank P. Fiedler for error-checking and editing the thermosalinograph data files. We greatly appreciate the ArcGIS help provided by J. Frew, M. Colee, and R. Cosgrove, and K. Ireson's help in debugging Matlab code. H. Orr's graphical assistance is much appreciated. We thank J. Michaelsen, L. Washburn, W. J. Richardson, and 4 anonymous reviewers for their thoughtful comments and suggestions on this manuscript. Funding for this project was provided by the Strategic Environmental Research and Development Program (SERDP), under Conservation Project CS-1391, and the Southwest Fisheries Science Center. 


\section{LITERATURE CITED}

Akaike H (1973) Information theory and an extension of the maximum likelihood principle. In: Petran BN, Csàaki F (eds) The 2nd international symposium on information theory. Akadèemiai Kiadi, Budapest, p 267-281

Barlow J (2003) Preliminary estimates of the abundance of cetaceans along the U.S. west coast: 1991-2001. Report No. LJ-03-03, Southwest Fisheries Science Center, La Jolla, CA

Barlow J, Forney KA (2007) Abundance and density of cetaceans in the California Current ecosystem. Fish Bull 105:509-526

Barlow J, Gerrodette T, Forcada J (2001) Factors affecting perpendicular sighting distances on shipboard linetransect surveys for cetaceans. J Cetacean Res Manag 3: 201-212

Barlow J, Ferguson MC, Becker EA, Redfern JV and others (2009) Predictive modeling of cetacean densities in the eastern Pacific Ocean. NOAA Tech Memo NMFS-SWFSC 444, La Jolla, CA

Baumgartner MF, Mullin KD, May LN, Leming TD (2001) Cetacean habitats in the northern Gulf of Mexico. Fish Bull 99:219-239

Buckland ST, Anderson DR, Burnham KP, Laake JL, Borchers DL, Thomas L (2001) Introduction to distance sampling: estimating abundance of biological populations. Oxford University Press, Oxford

Calambokidis J, Steiger GH, Straley JM, Herman LM and others (2001) Movements and population structure of humpback whales in the North Pacific. Mar Mamm Sci 17:769-794

Calambokidis J, Chandler T, Schlender L, Steiger GH, Douglas A (2003) Research on humpback and blue whales off California, Oregon, and Washington in 2002. Final contract report to Southwest Fisheries Science Center, National Marine Fisheries Service, La Jolla, CA

Cañadas A, Sagarminaga R, García-Tiscar S (2002) Cetacean distribution related with depth and slope in the Mediterranean waters off southern Spain. Deep-Sea Res I 49: 2053-2073

Davis RW, Fargion GS, May N, Leming TD and others (1998) Physical habitat of cetaceans along the continental slope in the north-central and western Gulf of Mexico. Mar Mamm Sci 14:490-507

Davis RW, Ortega-Ortiz JG, Ribic CA, Evans WE and others (2002) Cetacean habitat in the northern oceanic Gulf of Mexico. Deep-Sea Res I 49:121-142

Dohl TP, Guess RC, Duman ML, Helm RC (1983) Cetaceans of central and northern California, 1980-1983: status, abundance, and distribution. Contract No. 14-12-0001-29090, NTIS Catalog No. PB85-183861, prepared for Pacific OCS Region, Minerals Management Service. US Department of the Interior, Washington, DC

- Doniol-Valcroze T, Berteaux D, Larouche P, Sears R (2007) Influence of thermal fronts on habitat selection by four rorqual whale species in the Gulf of St. Lawrence. Mar Ecol Prog Ser 335:207-216

Etnoyer P, Canny D, Mate BR, Morgan LE, Ortega-Ortiz JG, Nichols WJ (2006) Sea-surface temperature gradients across blue whale and sea turtle foraging trajectories off the Baja California Peninsula, Mexico. Deep-Sea Res II 53: $340-358$

Evans WE (1994) Common dolphin, white-bellied porpoise Delphinus delphis Linnaeus, 1758. In: Ridgway SH, Harrison Sir R (eds) Handbook of marine mammals, Vol 5. The first book of dolphins. Academic Press, London
Ferguson MC, Barlow J, Fiedler P, Reilly SB, Gerrodette T (2006) Spatial models of delphinid (family Delphinidae) encounter rate and group size in the eastern tropical Pacific Ocean. Ecol Modell 193:645-662

Finney DJ (1941) On the distribution of a variate whose logarithm is normally distributed. JR Stat Soc Suppl 7: 155-161

Forney KA (1999) Trends in harbor porpoise abundance off central California, 1986-95: Evidence for interannual change in distribution? J Cetacean Res Manag 1:73-80

Forney KA (2000) Environmental models of cetacean abundance: reducing uncertainty in population trends. Conserv Biol 14:1271-1286

Forney KA, Barlow J (1998) Seasonal patterns in the abundance and distribution of California cetaceans, 1991-1992. Mar Mamm Sci 14:460-489

Hamazaki T (2002) Spatiotemporal prediction models of cetacean habitats in the mid-western North Atlantic Ocean (from Cape Hatteras, North Carolina, USA to Nova Scotia, Canada). Mar Mamm Sci 18:920-939

Hastie TJ, Tibshirani RJ (1990) Generalized additive models, Vol 43. Chapman \& Hall/CRC, Boca Raton, FL

Hedley SL, Buckland ST, Borchers DL (1999) Spatial modelling from line transect data. J Cetacean Res Manag 1:255-264

> Hooker SK, Whitehead H, Gowans S (1999) Marine protected area design and the spatial and temporal distribution of cetaceans in a submarine canyon. Conserv Biol 13: 592-602

Hui CA (1979) Undersea topography and distribution of dolphins of the genus Delphinus in the Southern California Bight. J Mammal 60:521-527

> Jaquet N, Whitehead H (1996) Scale-dependent correlation of sperm whale distribution with environmental features and productivity in the South Pacific. Mar Ecol Prog Ser 135: $1-9$

Jefferson TA, Newcomer MW, Leatherwood S, Van Waerebeek K (1994) Right whale dolphins Lissodelphis borealis (Peale, 1848) and Lissodelphis peronni (Lacepede, 1804). In: Ridgway SH, Harrison Sir R (eds) Handbook of marine mammals, Vol 5. The first book of dolphins. Academic Press, London

Kaschner K, Watson R, Trites AW, Pauly D (2006) Mapping world-wide distributions of marine mammal species using a relative environmental suitability (RES) model. Mar Ecol Prog Ser 316:285-310

Kinzey D, Olson P, Gerrodette T (2000) Marine mammal data collection procedures on research ship line-transect surveys by the Southwest Fisheries Science Center. Report No. LJ-00-08, Southwest Fisheries Science Center, La Jolla, CA

Leatherwood S, Reeves RR, Perrin WF, Evans WE (1982) Whales, dolphins and porpoises of the eastern North Pacific and adjacent arctic waters. A guide to their identification. NOAA Tech Rep NMFS Circular 444, Rockville, MD

Lynn RJ, Simpson JJ (1987) The California Current system: the seasonal variability of its physical characteristics. J Geophys Res C 92:12947-12966

Mann K, Lazier JR (2006) Dynamics of marine ecosystems: biological-physical interactions in the oceans, 3rd edn. Blackwell Publishing, Boston, MA

McCullagh P, Nelder JA (1989) Generalized linear models, Vol 37. Chapman \& Hall, New York

Moore SE, Watkins WA, Daher MA, Davies JR, Dahlheim ME (2002) Blue whale habitat associations in the northwest Pacific: analysis of remotely-sensed data using a Geographic Information System. Oceanography (Wash DC) 15:20-25 
Perrin WF, Wilson CE, Archer FI II (1994) Striped dolphin Stenella coeruleoalba (Meyen, 1833). In: Ridgway SH, Harrison Sir R (eds) Handbook of marine mammals, Vol 5. The first book of dolphins. Academic Press, London

Philbrick VA, Fiedler PC, Reilly SB (1993) Report of ecosystem studies conducted during the 1991 California coastal marine mammal survey aboard the research vessel McArthur. NOAA Tech Memo NMFS-SWFSC 184, La Jolla, CA

Philbrick VA, Fiedler PC, Balance LT, Demer DA (2003) Report of ecosystem studies conducted during the 2001 Oregon, California, and Washington (ORCAWALE) marine mammal survey on the research vessels David Starr Jordan and McArthur. NOAA Tech Memo NMFS-SWFSC 349, La Jolla, CA

Redfern JV, Ferguson MC, Becker EA, Hyrenbach KD and others (2006) Techniques for cetacean-habitat modeling: a review. Mar Ecol Prog Ser 310:271-295

Redfern JV, Barlow J, Ballance LT, Gerrodette T, Becker EA (2008) Absence of scale dependence in dolphin-habitat

Editorial responsibility: Hans Heinrich Janssen, Oldendorf/Luhe, Germany models for the eastern tropical Pacific Ocean. Mar Ecol Prog Ser 363:1-14

Smith RJ (1993) Logarithmic transformation bias in allometry. Am J Phys Anthropol 90:215-228

Torres LG, Rosel PE, D'Agrosa C, Read AJ (2003) Improving management of overlapping bottlenose dolphin ecotypes through spatial analysis and genetics. Mar Mamm Sci 19:502-514

US Department of Commerce, NOAA, NGDC (National Oceanic and Atmospheric Administration, National Geophysical Data Center) (2006) 2-minute gridded global relief data (ETOPO2v2). Available at: www.ngdc.noaa. gov/mgg/fliers/06mgg01.html (accessed on: 9 November 2006)

Waring GT, Fairfield CP, Ruhsam CM, Sano M (1993) Sperm whales associated with Gulf Stream features off the northeastern USA shelf. Fish Oceanogr 2:101-105

Wessel P, Smith WHF (1998) New, improved version of the generic mapping tools released. Eos Trans AGU 79:579

Submitted: January 6, 2009; Accepted: June 7, 2010

Proofs received from author(s): August 17, 2010 